\title{
AVANCES EN LA PROTECCIÓN Y CONSERVACIÓN DEL MEDIO MARINO ESPAÑOL. EL NUEVO MARCO PARA LA ORDENACIÓN DEL ESPACIO MARÍTIMO
}

\author{
Josep Ramon Fuentes Gasó \\ Profesor titular de Derecho Administrativo \\ Universitat Rovira i Virgili \\ josepramon.fuentes@urv.cat
}

Recibido: 07/07/2017 Aceptado: 05/09/2017

\section{RESUMEN:}

Este trabajo tiene como objeto analizar los instrumentos de planificación del medio marino en el ordenamiento jurídico español. En el contexto de la política marítima integrada de la Unión Europea y de las estrategias marinas, reguladas en la Ley $41 / 2010$, de 29 de diciembre, de protección del medio marino, se destaca el Real Decreto 363/2017, de 8 de abril, por el que se establece un marco para la ordenación del espacio marítimo. Este real decreto dota al espacio marino español de un marco regulador integrador más avanzado. Dispone la determinación y aplicación de una ordenación del espacio marítimo con el fin de fomentar el crecimiento sostenible de las economías marítimas, y el desarrollo sostenible de los espacios marinos y el aprovechamiento sostenible de los recursos marinos. Y para lograr estos objetivos se ha previsto la aprobación de planes de ordenación para cada una de las demarcaciones marinas españolas, que se condicionarán a los diferentes usos y actividades que se desarrollan en las aguas marinas. Esto, sin duda, promueve asegurar que se mantiene el buen estado ambiental. 


\section{RESUM:}

Aquest treball té com a objecte analitzar els instruments de planificació del medi marí a l'ordenament jurídic espanyol. En el context de la política marítima integrada de la Unió Europea, i de les estratègies marines, regulades a la Llei de Protecció del Medi Marí, es destaca el Reial Decret 363/2017, de 8 d'abril, pel qual s'estableix el nou marc jurídic per a l'ordenació de l'espai marítim. Aquest Reial decret dota l'espai marí espanyol d'un marc regulador integrador més avançat. Disposa la determinació i aplicació d'una ordenació de l'espai marítim per tal de fomentar: el creixement sostenible de les economies marítimes; el desenvolupament sostenible dels espais marins i l'aprofitament sostenible dels recursos marins. I per aconseguir aquests objectius es preveu l'aprovació de plans d'ordenació per a cadascuna de les demarcacions marines espanyoles que es condicionaran als diferents usos i activitats que desenvolupen en les aigües marines. Això, sens dubte, promou assegurar que es mantingui el bon estat ambiental.

\section{ABSTRACT:}

This study has as object to analyse the marine planning instruments in the Spanish legal system. In the context of the EU's integrated maritime policy and marine strategies, regulated in the Marine Environment Protection Law, Royal Decree 363/2017, of 8 April, establishing the new Legal framework for the management of maritime space. This Royal Decree provides the Spanish marine space with a more advanced integrating regulatory framework. It provides for the determination and application of maritime spatial planning in order to foster: the sustainable growth of maritime economies; the sustainable development of marine spaces and the sustainable use of marine resources. And to achieve these objectives, it is planned to approve management plans for each of the Spanish marine demarcations that are going to be conditioned to the different uses and activities that they develop in the marine waters. This undoubtedly promotes ensuring that good environmental status is maintained. 
PALABRAS CLAVE: estrategia marina - áreas marinas protegidas - medio marino - enfoque integral.

PARAULES CLAU: estratègia marina - àrees marines protegides - medi marí- enfocament integral.

KEYWORDS: marine strategies - marine protected areas - marine environment —integral aprroach.

SUMARIO: I. Introducción. II. La naturaleza jurídica del medio marino. III. La política marítima integrada de la Unión Europea. IV. La protección y conservación del medio marino en el ordenamiento jurídico español. 1. Las áreas marinas protegidas. 2. La Ley de Protección del Medio Marino. A. Las estrategias marinas. B. La Red de Áreas Marinas Protegidas. i. Los espacios marinos incluidos y su atribución competencial. ii. El Plan Director de la Red de Áreas Marinas: instrumento de coordinación de las comunidades autónomas y el Estado. V. El nuevo marco para la ordenación del espacio marítimo: el Real Decreto 363/2017, de 8 de abril. 1. Finalidad y objetivos. 2. Ámbito de aplicación. 3. Los planes de ordenación del espacio marítimo. A. El contenido de los planes de ordenación. VI. A modo de conclusiones: hacia una verdadera protección integrada del medio marino. VII. Bibliografía.

\section{INTRODUCCIÓN}

Los espacios marinos y sus costas son muy importantes para el bienestar de los ciudadanos, ya que, además de ser el lugar donde la mayor parte de la población reside, regulan el clima y son una fuente importante de alimentos, energía y recursos genéticos, así como una vía fundamental de transporte y comunicación ${ }^{1}$. De esta forma, los ecosistemas marinos desempeñan un papel determinante en nuestras vidas y son un factor importante para el desarrollo económico, el bienestar social y la calidad de vida.

A pesar de la importancia del mar, en nuestro ordenamiento jurídico se ha tardado mucho en ordenar y proteger el medio marino de forma integrada. Hasta la última década del siglo XX solo se adoptaron regulaciones sectoriales

\footnotetext{
1 ORTIZ GARCíA, M., La conservación de la biodiversidad marina: las áreas marinas protegidas, Comares, Granada, 2002, p. 31 y ss.
} 
sobre el medio marino, sin una visión de conjunto que integrara las múltiples actividades que se realizan en el mar $^{2}$.

Pero desde la Unión Europea se ha impulsado una política marítima integrada. Este enfoque integral del medio marino se ha introducido en nuestro ordenamiento jurídico a partir de la transposición de la Directiva 2008/56/CE del Parlamento Europeo y del Consejo, de 17 de junio de 2008, por la que se establece un marco de acción comunitaria para la política del medio marino, mediante la Ley 41/2010, de 29 de diciembre, de protección del medio marino (LPMM). En este contexto recientemente se ha aprobado el Real Decreto $363 / 2017$, de 8 de abril, mediante el cual se incorporará al derecho español la Directiva 2014/89/UE, del Parlamento Europeo y del Consejo, de 23 de julio de 2014, por la que se establece un marco para la ordenación del espacio marítimo.

Como se analiza en este trabajo, la ordenación que establece la LPMM sienta las bases para conseguir la armonización y concreción de la tutela del medio marino mediante la planificación, estrategias marinas, como instrumento esencial para coordinar los diferentes sectores y actividades relacionados con el medio marino. Por su parte, el Real Decreto 363/2017 establece el nuevo marco para la ordenación del espacio marítimo, cuyo objetivo es fomentar el crecimiento sostenible de las economías marítimas, el desarrollo de los espacios marinos y el aprovechamiento de los recursos marinos.

\section{LA NATURALEZA JURÍDICA DEL MEDIO MARINO}

El medio marino, considerado como el conjunto de las aguas sobre las que el Estado ejerce soberanía y jurisdicción, incluyendo el lecho, el subsuelo y sus recursos naturales, reúne dos condiciones que determinan el análisis de su

\footnotetext{
${ }^{2}$ Sobre la ausencia de tratamiento global de la materia, véanse ORTIZ GARCÍA, M., "La Ley de protección del medio marino: hacia la gobernanza marítima", Revista Catalana de Dret Ambiental, vol. II, núm. 2, 2011, p. 5; ZAMBONINO PULITO, M., La protección jurídicoadministrativa del medio marino: tutela ambiental y transporte marítimo, Tirant lo Blanch, Valencia, 2001, p. 28 y ss.
} 
naturaleza jurídica: su condición natural de bien de valor ambiental y su condición jurídica de bien de dominio público ${ }^{3}$.

Estas dos características confieren al medio marino una posición singular en nuestro ordenamiento jurídico, por cuanto determinan una protección constitucional reforzada: como parte del medio ambiente (art. 45 Constitución española, CE) y como bien demanial (art. 132.2 CE).

El artículo $45 \mathrm{CE}$ reconoce el derecho de todos a disfrutar de un medio ambiente adecuado y el deber de conservarlo. Además, establece que los poderes públicos velarán por la utilización racional de todos los recursos naturales con el fin de proteger y mejorar la calidad de vida y defender y restaurar el medio ambiente.

Esta perspectiva respecto al medio marino se observa en la propia finalidad de la LPMM, que busca lograr o mantener el buen estado ambiental del medio marino a través de su planificación, conservación, protección y mejora (art. 1 LPMM). Esta necesidad de proteger el medio marino y lograr el mencionado "buen estado ambiental" es consecuencia de las amenazas a las que se ve sometido. Como detalla el preámbulo de la Ley, "es objeto de numerosas actividades humanas, y está sujeto a importantes presiones e impactos. La pesca, la navegación, las instalaciones de producción energética, el turismo y la industria de la biotecnología son algunos de los sectores económicos que se llevan a cabo o afectan al medio marino. Los vertidos urbanos, industriales y fruto de la navegación, y la consecuente pérdida de calidad del medio marino, la eliminación o alteración de hábitats y poblaciones de especies marinas, la sobreexplotación de recursos marinos vivos, el ruido submarino, la presión urbanística, o las alteraciones derivadas del cambio climático, son algunas de las presiones a las que están sujetos nuestros mares y océanos”.

Además, el medio marino está configurado como un bien de dominio público. Así, el apartado segundo del artículo 132 CE declara de dominio público estatal ciertas dependencias demaniales, entre las que figuran el mar territorial y los

\footnotetext{
${ }^{3}$ GARCÍA PÉREZ, M., "El marco constitucional y legal de los bienes de dominio público marino en España. Ámbito de aplicación, naturaleza y régimen de medio marino en la Ley 41/2010, de protección del medio marino", Arana García, E. y Sanz Larruga, F. J. (dirs.), La ordenación jurídica del medio marino en España. Estudios sobre la Ley 41/2010, de protección del medio marino, Thomson Reuters, Cizur Menor, 2012, p. 257.
} 
recursos naturales de la zona económica y la plataforma continental ${ }^{4}$. Este reconocimiento constitucional actúa como límite indisponible para el legislador. La LPMM lo desarrolla y en su artículo 3 establece que la utilización de las aguas, incluidos el lecho, el subsuelo y los recursos naturales, será libre, pública y gratuita para los usos compatibles con su naturaleza de bien de dominio público, de conformidad con lo establecido en la Ley 22/1988, de 28 de julio, de $\operatorname{Costas}^{5}$, y con la preservación de su integridad, sin perjuicio de las

${ }^{4}$ Esta consideración tiene un largo recorrido en la tradición romanística europea. El mar, el aire
y el agua fueron considerados res nullius, res communes omnium o res publicae iuris gentium.
Respecto a estos bienes recogidos en la misma CE, vid., entre los numerosos autores que
estudian estas cuestiones, CALERO RODRÍGUEZ, J. R., Régimen jurídico de las costas
españolas, Aranzadi, Pamplona, 1995; GONZÁLEZ SALINAS, J., Régimen jurídico actual de la
propiedad en las costas, Civitas, Madrid, 2000; MEILÁN GIL, J. L., "El concepto de dominio
público marítimo-terrestre en el Proyecto de LC", Revista española de Derecho Administrativo,
núm. 59, jul.-sep., 1988; MEILÁN GIL, J. L., "El dominio público natural y la legislación de
costas", RAP, núm. 139, ene.-abr., 1996; MENÉNDEZ REXACH, A., "La configuración del
dominio público marítimo-terrestre en la LC", Estudios Territoriales, núm. 34, sep.-dic., 1990;
RODRÍGUEZ LÓPEZ, P., Comentarios a la LC, Doctrina y Jurisprudencia, Dijusa, Madrid, 2003.

${ }^{5} \mathrm{Ha}$ experimentado una modificación sustancial mediante la Ley $2 / 2013$, de 29 de mayo, de protección y uso sostenible del litoral. Sobre esta reforma, véanse, entre otros, AGUIRRE I FONT, J. M., "L'impacte de la reforma de la Llei de Costes sobre el règim jurídic del litoral català: especial referència a la reducció de l'espai protegit i a les invasions competencials", Revista catalana de dret públic, núm. 47, 2013; AGUIRRE I FONT, J. M., El régimen jurídico del litoral catalán. Especial referencia a la reforma de la Ley de Costas operada por la Ley 2/2013 y al nuevo Reglamento General de Costas aprobado por el Real Decreto 876/2014. Atelier, Barcelona, 2014; AGUIRRE I FONT, J. M., El régimen jurídico del litoral catalán. Especial referencia a la reforma de la Ley de Costas operada por la Ley 2/2013, de 29 de mayo, de protección y uso sostenible del litoral y de modificación de la Ley 22/1988, de 28 de julio, de Costas, Atelier, Barcelona, 2015; ARANA GARCÍA, E. y NAVARRO ORTEGA, A., "La Ley de Protección y Uso Sostenible del Litoral: ¿un giro hacia lo desconocido?", Revista Vasca de Administración Pública, núm. 97, sep.-dic. 2013, pp. 21-60; ARANA GARCÍA, E., "La Ley 2/2013 de Protección y Uso Sostenible del Litoral: las 'soluciones singulares' y las nuevas medidas relativas a los riesgos naturales en la costa", Revista de derecho urbanístico y medio ambiente, núm. 295, 2015, pp. 101-135; CARRO FERNÁNDEZ-VALMAYOR, J. L., FERREIRA FERNÁNDEZ, J. y NOGUEIRA LÓPEZ, A., La nueva regulación de las costas, INAP, Madrid, 2014; CHINCHILLA PEINADO, J. A., "La Ley 2/2013, de Protección y Uso Sostenible del Litoral, y el Real Decreto 876/2014, de 10 de octubre, por el que se aprueba el Reglamento General de costas", Revista de derecho urbanístico y medio ambiente, núm. 295, 2015, pp. 137-180; GIFREU I FONT, J., "La protección y utilización del demanio marítimo-terrestre a propósito de la reciente jurisprudencia constitucional. Hacia una ordenación integrada y sostenible del litoral de Cataluña", Práctica Urbanística, Sección Estudios, Ed. La Ley, núm. 140, 2016, pp. 1-35; TORRES-FERNÁNDEZ NIETO, J. J., FERNÁNDEZ DE TROCONIZ, F. C., OLANO ESPINOSA, C., MENÉNDEZ MENÉNDEZ, A., GONZÁLEZ DE OLANO, G., CANCER MICHOT, P. y RISQUETE, J. L., Comentario a la Ley 2/2013, de 29 de mayo, de Protección y Uso Sostenible del Litoral y de Modificación de la Ley 22/1988, de Costas, Thomson Reuters Aranzadi, Cizur Menor, 2014. MENÉNDEZ REXACH, A., "Definición legal de la ribera del mar: novedades del Reglamento de Costas", Revista de derecho urbanístico y medio ambiente, núm. 295, 2015, pp. 17-44. NÚÑEZ LOZANO, M. C., La reforma de la Ley de Costas de 2013, Tirant lo Blanch, Valencia, 2013. PÉREZ GÁLVEZ, J. F. y ALEMÁN MONTERREAL, A. (coords.), Costas y urbanismo: el litoral tras la Ley 2/2013, de protección y uso sostenible del litoral y de modificación de la Ley de Costas, La Ley-EI Consultor, Madrid, 2013. RODRÍGUEZ BEAS, M., "El régimen jurídico de las costas. Especial referencia a la reforma de la Ley de 
facultades de las comunidades autónomas (CC. AA.) de establecer normas adicionales de protección en su territorio ${ }^{6}$. Así sucede, por ejemplo, en el Estatuto de Autonomía de Cataluña (EAC), que establece el medio ambiente como una competencia compartida entre el Estado y la Generalitat de Catalunya, a la que atribuye la competencia para disponer normas adicionales de protección ${ }^{7}$.

Esta condición de bien de dominio público se ha utilizado en nuestro ordenamiento jurídico para atribuir o reservar la competencia a favor del Estado. Pero dicha consideración se ha visto afectada por la jurisprudencia constitucional, que ha tenido ocasión de dilucidar conflictos de competencias sobre este tipo de bienes demaniales. El Tribunal Constitucional (TC) tiene asentada la doctrina de que el dominio público no es un título atributivo de competencias, sino más bien la facultad-deber de la Administración de garantizar el bienestar de los ciudadanos en condiciones de libertad e igualdad y en un entorno medioambiental adecuado. Resulta extensible al medio marino el pronunciamiento del TC respecto al dominio público marítimo-terrestre en la STC 149/1991, sobre la Ley de Costas: "Esta naturaleza y estas características de la zona marítimo-terrestre no se reducen, como es bien sabido, al simple hecho físico de ser esa zona el espacio en el que entran en contacto el mar y la tierra. De esa situación derivan una serie de funciones sociales que la Carta

Costas a la luz de la jurisprudencia del Tribunal Constitucional más reciente", Revista Catalana de Dret Ambiental, vol. 7, núm. 1, 2016, pp. 1-50. SANZ LARRUGA, F. J., "La reforma de la Ley de Costas o la apertura de la Caja de Pandora", Revista Aranzadi de Derecho Ambiental, núm. 25, 2013, pp. 11-20. SANZ LARRUGA, F. J., "Temores y expectativas ante la reforma de la ley de Costas", López Ramón, F. (coord.), Observatorio de Políticas Ambientales 2013, Thomson Reuters Aranzadi, Cizur Menor, 2013. SANZ LARRUGA, F. J., "La reforma de la Ley de Costas o la puesta en valor económico del litoral", López Ramón, F. (coord.), Observatorio de Políticas Ambientales 2014, Thomson Reuters Aranzadi, Cizur Menor, 2014, pp. 463-485.

${ }^{6}$ La Sentencia del Tribunal Constitucional (STC) 1956/1995, de 26 de noviembre, fundamento jurídico (FJ), dispone que las CC. AA. "pueden también complementar o reforzar los niveles de protección previstos en esa legislación básica, siempre que esas medidas legales autonómicas sean compatibles, no contradigan, ignoren, reduzcan o limiten la protección establecida en la legislación básica del Estado". En el mismo sentido se pronuncia la STC 196/1996, de 28 de noviembre, FJ 2. ${ }^{\circ}$. Vid. VILLANUEVA CUEVAS, A., PUNZÓN MORALES, J. y SÁNCHEZ RODRÍGUEZ, F., "La protección medioambiental de las costas", Ortega Álvarez, L. I., Alonso García, M. C. y De Vicente Martínez, R. (coord.), Tratado de derecho ambiental, Tirant lo Blanch, Valencia, 2013.

${ }^{7}$ EI EAC atribuye a la Generalitat de Catalunya competencias en materias relacionadas con el medio ambiente, como pesca (art. 119.2) u ordenación del territorio y del paisaje y del litoral y urbanismo (art. 149). Vid. CASADO CASADO, L. y FUENTES I GASÓ, J. R., Medi ambient $i$ ens locals, CEDECS, Barcelona, 2008, pp. 50-51. 
Europea del Litoral resume, en el primero de sus apartados, señalando que es esencial para el mantenimiento de los equilibrios naturales que condicionan la vida humana, ocupa un lugar estratégico en el desarrollo económico y en la reestructuración de la economía mundial, es soporte de las actividades económicas y sociales que crean empleo para la población residente, es indispensable para el recreo físico y psíquico de las poblaciones sometidas a la presión creciente de la vida urbana y ocupa un lugar esencial en las satisfacciones estéticas y culturales de la persona humana. Para servir a estas funciones el legislador estatal no sólo está facultado, sino obligado, a proteger el demanio marítimo-terrestre a fin de asegurar tanto el mantenimiento de su integridad física y jurídica, como su uso público y sus valores paisajísticos" ${ }^{8}$.

\section{LA POLÍTICA MARÍTIMA INTEGRADA DE LA UNIÓN EUROPEA}

La Unión Europea desde hace años desarrolla una política ambiental que proporciona un marco de protección efectivo para los mares y océanos. Así, ha aprobado una serie de instrumentos jurídicos que asumen la necesidad de superar los planteamientos parciales que tradicionalmente se venían aplicando al litoral, imponiendo una perspectiva holística e integral en la protección del medio marino ${ }^{9}$ y la gobernanza como método para integrar las distintas políticas sectoriales y posibilitar los fines propuestos desde la participación de todos los interesados en el proceso de planificación ${ }^{10}$.

De esta forma, se ha incluido la protección del medio marino en el desarrollo de la política marítima integrada $(\mathrm{PMI})^{11}$, la cual engloba cuestiones tan diversas como el transporte marítimo, la competitividad de las empresas marítimas, la investigación científica, la pesca y la protección del medio marino. La

\footnotetext{
${ }^{8} \mathrm{FJ} 1 .^{\circ} \mathrm{D}$.

${ }^{9}$ ARANA GARCÍA, E., "La Ley 41/2010, de protección del medio marino como nuevo marco de ordenación de los mares y océanos españoles. Consideraciones generales, estructura y contenido de la norma", Arana García y Sanz Larruga (dirs.), La ordenación... op. cit., p. 214.

${ }^{10}$ ZAMORANO WISNES, J., "Ordenación de los espacios marítimos y de las zonas costeras del Mediterráneo", Juste Ruiz, J., Bou Franch, V. (dirs.) y Sánchez Patrón, J. M. (coord.), Derecho del mar y sostenibilidad ambiental en el Mediterráneo, Tirant lo Blanch, Valencia, 2014, p. 471.

${ }^{11}$ Entre la doctrina se puede destacar a NUÑEZ LOZANO, M. C., "La política marítima integrada de la Unión Europea y la estrategia comunitaria de gestión integrada de las zonas costeras", Arana García y Sanz Larruga (dirs.), La ordenación... op. cit., p. 189 y ss.
} 
configuración de la PMI descansa "en el reconocimiento claro de la interconexión de todo lo relativo a los océanos y mares europeos y de que las políticas relacionadas con el mar deben formularse conjuntamente para poder obtener los resultados perseguidos"12.

Esto se ha desarrollado dentro de la PMI mediante la aprobación de instrumentos jurídicos que tienen en cuenta el mar y sus ecosistemas de una forma interrelacionada como la Directiva Marco del Agua $^{13}$, la Directiva Marco sobre la Estrategia Marina ${ }^{14}$, el Protocolo relativo a la gestión integrada de las zonas costeras del Mediterráneo del Convenio de Barcelona ${ }^{15}$, la Directiva de Aves y la Directiva de Hábitats ${ }^{16}$. Sin embargo, esta idea se fue fraguando en otros textos de carácter soft law ${ }^{17}$ : la Comunicación de la Comisión al Consejo y al Parlamento Europeo, de 2 de octubre de 2002, "Hacia una estrategia de protección y conservación del medio ambiente marino" ${ }^{18}$; Comunicación de la Comisión al Consejo y al Parlamento Europeo, de 24 de octubre de 2005, "Estrategia temática sobre la protección y la conservación del medio ambiente

\footnotetext{
${ }^{12}$ COM (2007) 575 final. Una política marítima integrada para la Unión Europea, p. 2.

${ }^{13}$ Directiva 2000/60/CE del Parlamento Europeo y del Consejo, de 23 de octubre de 2000, por la que se establece un marco comunitario de actuación en el ámbito de la política de aguas.

${ }^{14}$ Directiva 2008/56/CE del Parlamento Europeo y del Consejo, de 17 de junio de 2008, por la que se establece un marco de acción comunitaria para la política del medio marino.

${ }^{15}$ Convenio para la Protección del Medio Marino y de la Región Costera del Mediterráneo, adoptado en Barcelona el 16 de febrero de 1976, y enmendado el 10 de junio de 1995, en el marco del cual se adopta este protocolo, cuyo objetivo es establecer un marco común para la gestión integrada de las zonas costeras (ICZM) del mar Mediterráneo, que entró en vigor el 24 de marzo de 2011 (Protocolo GIZC). Para un análisis de este protocolo, véase GARCIAA RICO, E., "La gestión integrada de las zonas costeras: avances recientes", Juste Ruiz, J., Bou Franch, V. (dirs.) y Sánchez Patrón, J. M. (coord.), Derecho del mar y sostenibilidad ambiental en el Mediterráneo, Tirant lo Blanch, Valencia, 2014, p. 483 y ss.

${ }^{16}$ Directiva 2009/147/CE del Parlamento Europeo y del Consejo, de 30 de noviembre de 2009, relativa a la conservación de las aves silvestres, y Directiva 92/43/CEE del Consejo, de 21 de mayo de 1992, relativa a la conservación de los hábitats naturales y de la fauna y flora silvestres.

${ }^{17}$ En relación con el soft law y su valor normativo, vid. FUENTES I GASÓ, J. R., "Buenas prácticas y códigos de conducta: ¿Sustitutivos de la legislación?", Speyerer Forchungsberichte, núm. 281, 2015, pp. 137-168.
}

${ }^{18}$ COM (2002) 539 final. 
marino"19; y la Comunicación "Hoja de ruta para la ordenación del espacio marítimo: creación de principios comunes en la Unión Europea”, de $2008^{20}$.

Además, en el Libro Azul de la Política Marítima Integrada y en el Plan de Acción para una Política Marítima Integrada de la Unión Europea, la ordenación del espacio marítimo se presentaba como uno de los instrumentos intersectoriales que contribuyen a la aplicación de la PMI.

El pilar medioambiental de la PMI lo constituye la Directiva 2008/56/CE ${ }^{21}$ o Directiva Marco sobre la Estrategia Marina, que tiene como objetivo proteger y restablecer los ecosistemas marinos europeos y garantizar la viabilidad ecológica de las actividades económicas relacionadas con el medio marino antes del año $2020^{22}$. Para ello, establece una serie de objetivos ambientales que han de lograr la conservación de un medio marino sostenible a través de la implementación de instrumentos de planificación, así como la elaboración de un programa de medidas y mejoras en los sistemas de evaluación y control. En este sentido, se elaborarán y aplicarán estrategias marinas a fin de: proteger y preservar el medio marino, evitar su deterioro o, en la medida de lo posible, recuperar los ecosistemas marinos en las zonas que se hayan visto afectadas negativamente; y prevenir y reducir los vertidos al medio marino con vistas a eliminar progresivamente la contaminación, según se define en el artículo 3.8, para velar por que no se produzcan impactos o riesgos graves para la biodiversidad marina, los ecosistemas marinos, la salud humana o los usos legítimos del mar (art. 1.2).

\footnotetext{
${ }^{19} \operatorname{COM}(2005) 504$.

${ }^{20}$ Vid. Comunicación de la Comisión al Consejo, al Parlamento Europeo, al Comité Económico y Social y al Comité de las Regiones, de 24 de enero de 2001, sobre el Sexto Programa de Acción de la Comunidad Europea en materia de Medio Ambiente: "Medio ambiente 2010: el futuro está en nuestras manos" [COM (2001) 31 final]. Decisión 1600/2002/CE del Parlamento y del Consejo, de 22 de julio de 2002, por la que se establece el Sexto Programa de Acción Comunitario en materia de Medio Ambiente.

${ }^{21}$ Como afirma ARANA GARCÍA, es el instrumento más determinante para el desarrollo de una política marítima integrada y actúa como un punto de inflexión decisivo al introducir carácter vinculante a sus disposiciones. Vid. ARANA GARCÍA, "La Ley 41/2010...", op. cit., p. 216.

${ }^{22}$ También pueden consultarse sobre este tema: Libro Azul de la Política Marítima Integrada COM (2007) 575 final; la Comunicación "La Ordenación del Espacio Marítimo de la UE-Logros y Desarrollo Futuro" COM (2010) 771 final; y el Informe de la Comisión COM (2009) 540 final "Estado de situación de la política marítima integrada de la Unión".
} 
Asimismo, esta directiva establece principios comunes sobre cuya base los Estados miembros deben elaborar, en colaboración con los Estados miembros y terceros Estados, sus propias estrategias para alcanzar un estado ecológico satisfactorio de las aguas marinas bajo su jurisdicción. Para ello, los Estados miembros deben aprobar una estrategia marina para cada región o subregión marina. Estas estrategias marinas constituyen el marco general al que deberán ajustarse necesariamente las diferentes políticas sectoriales y actuaciones administrativas con incidencia en el medio marino de acuerdo con lo establecido en la legislación sectorial.

Con objeto de promover la coexistencia sostenible de los usos y la distribución adecuada del espacio marítimo entre los usos pertinentes, debe implantarse un marco consistente en el establecimiento y la aplicación por parte de los Estados miembros de una ordenación del espacio marítimo que dé lugar a planes.

Por ello, se aprobó la Directiva 2014/89/UE del Parlamento Europeo y del Consejo, de 23 de julio de 2014, por la que se establece un marco para la ordenación del espacio marítimo, cuyo objetivo es fomentar el crecimiento sostenible de las economías marítimas, el desarrollo sostenible de los espacios marinos y el aprovechamiento sostenible de los recursos marinos.

\section{LA PROTECCIÓN Y CONSERVACIÓN DEL MEDIO MARINO EN EL ORDENAMIENTO JURÍDICO ESPAÑOL}

En España, la Ley 42/2007, de 13 de diciembre, del Patrimonio Natural y de la Biodiversidad (LPNB), introduce por primera vez una nueva categoría de espacio natural protegido pensada exclusivamente para proteger el medio marino, las áreas marinas protegidas ${ }^{23}$. Su predecesora, la Ley 4/1989, de 27 de marzo, de Conservación de los Espacios Naturales y de la Flora y Fauna Silvestres, establecía solamente categorías de espacios naturales protegidos pensadas para el medio terrestre, si bien eran aplicables a ámbitos costeros o marítimos (arts. 10.1 y 21.3), con los consabidos problemas competenciales

\footnotetext{
${ }^{23}$ A través del Real Decreto 1629/2011, de 14 de noviembre, por el que se declara como Área Marina Protegida y como Zona Especial de Conservación el espacio marino de El Cachucho, y se aprueban las correspondientes medidas de conservación, la primera de España.
} 
planteados desde la STC 195/1998, relativa a la Ley 6/1992, de 27 de marzo, por la que se declara Reserva Natural a las Marismas de Santoña y Noja.

Con este cambio legislativo podemos apreciar el salto cualitativo que supone la LPNB respecto a la protección del medio marino, puesto que introduce una figura específica ${ }^{24}$.

\section{Las áreas marinas protegidas}

Una definición de "área marina protegida" (AMP) comúnmente aceptada desde el ámbito científico y adoptada por la Unión Internacional para la Conservación de la Naturaleza (UICN) es "cualquier área intermareal o submareal terrestre, junto con el agua circundante, su flora y fauna asociada y sus características culturales, las cuales han sido preservadas por ley u otro medio efectivo de protección de una parte o todo un medio ambiente"25.

No obstante, en un sentido estricto, como afirma GIMÉNEZ CASALDUERO, es una técnica de gestión in situ de la biodiversidad del medio marino ${ }^{26}$. Sin embargo, bajo esta denominación de área marina protegida o cualquier otra denominación tradicional, como santuario o parque marino, podemos encontrar una regulación sectorial de un determinado uso o el objetivo de proteger a las poblaciones de una determinada especie ${ }^{27}$.

Según la LPNB, un espacio natural protegido se define en el artículo 28 como "los espacios del territorio nacional, incluidas las aguas continentales, y el medio marino, junto con la zona económica exclusiva y la plataforma continental, que cumplan al menos uno de los requisitos siguientes y sean declarados como tales: a) Contener sistemas o elementos naturales representativos, singulares, frágiles, amenazados o de especial interés

\footnotetext{
${ }^{24}$ Vid. ORTIZ GARCÍA, M., "La red de áreas marinas protegidas de España en la protección del medio marino", Arana García y Sanz Larruga (dirs.), La ordenación... op. cit., p. 349.

${ }^{25}$ UICN, Directrices para las categorías de manejo de áreas protegidas, Centro de Parques Nacionales y Áreas Protegidas (CPNAP) - Centro Mundial de Monitoreo de la Conservación (WCMC), Cambridge, 1995.

${ }^{26}$ GIMÉNEZ CASALDUERO, M., "Las áreas marinas protegidas: nuevas perspectivas a la luz de la Ley 42/2007, del patrimonio natural y de la biodiversidad", Revista Catalana de Dret Ambiental, núm. 1, 2010, p. 6.

27 Ibidem.
} 
ecológico, científico, paisajístico, geológico o educativo. b) Estar dedicados especialmente a la protección y el mantenimiento de la diversidad biológica, de la geodiversidad y de los recursos naturales y culturales asociados" 28 .

Pero es el artículo 33 LPNB el que introduce en España, con carácter básico, una figura de protección y conservación para el medio marino y define las AMP como los "espacios naturales designados para la protección de ecosistemas, comunidades o elementos biológicos o geológicos del medio marino, incluidas las áreas intermareal y submareal, que, en razón de su rareza, fragilidad, importancia o singularidad, merecen una protección especial”29.

Por tanto, según la citada legislación básica del Estado, las AMP son una más de las categorías de espacios naturales protegidos del artículo 30 LPNB. Además, los espacios marinos clasificados conforme a alguna de las categorías jurídicas de espacios naturales protegidos previstos por la Ley, como parques, reservas, monumentos, etc., podrán ser AMP, si bien adoptarán el régimen jurídico previsto para cada una de ellas ${ }^{30}$. De este modo, las AMP se configuran como una categoría individualizada, aunque, a su vez, según ORTIZ GARCÍA, constituyen un concepto que comprende el resto de categorías siempre que su ámbito espacial se oriente al medio marino ${ }^{31}$.

En conclusión, si se trata de un espacio marino de los delimitados en el artículo 33 LPNB, serán AMP cuando su objeto sea la protección de un espacio marino, ya sea mixto, es decir, marítimo-terrestre, o exclusivamente marino. Aunque tal

\footnotetext{
${ }^{28}$ Precepto modificado por el apartado diecinueve del artículo único de la Ley 33/2015, de 21 de septiembre, por la que se modifica la LPMM.

${ }^{29}$ Además, el citado precepto determina que estos espacios podrán ser incorporados a la Red de Áreas Marinas Protegidas de España regulada en la LPMM. Cabe señalar que este precepto ha sido reenumerado y redactado por el apartado veintitrés del artículo único de la Ley $33 / 2015$, de 21 de septiembre, por la que se modifica la LPMM. Sobre la caracterización de las AMB en la LPNB, vid. ORTIZ GARCíA, M., "La protección del medio marino", Noticias de la Unión Europea, núm. 307, 2010.

${ }^{30}$ GIMÉNEZ CASALDUERO, "Las áreas marinas protegidas...", op. cit., p. 8.

${ }^{31}$ ORTIZ GARCÍA define la AMP como "una técnica jurídica que otorga un régimen protector especial a un espacio marino - que puede estar vinculado al espacio terrestre- y localizado en cualquier espacio oceánico sea jurisdiccional o no, para la salvaguarda de los ecosistemas marinos relevantes y/o amenazados que contengan, mediante la declaración formal del órgano competente de acuerdo con la normativa de conservación de la naturaleza; que asimismo, posibilitará y regulará los usos que no impidan la capacidad de regeneración del medio, fundamentalmente, actividades de investigación y educativas, así como ciertas prácticas artesanales de pesca". Vid. ORTIZ GARCÍA, M., La gestión eficiente de la zona costera. Los parques marinos, Tirant lo Blanch, Valencia, 2003, p. 81.
} 
vez hubiera sido más adecuado distinguir entre parques marítimo-terrestres, si comprenden espacio terrestre, y parques marinos, si prevalece el elemento marino y su cercanía a la costa, reservando el de santuario marino para zonas alejadas $^{32}$.

\section{La Ley de Protección del Medio Marino}

La Ley 41/2010, de 29 de diciembre, de protección del medio marino (LPMM), incorpora al ordenamiento jurídico español la Directiva 2008/56/CE del Parlamento Europeo y del Consejo, de 17 de junio de 2008, por la que se establece un marco de acción comunitaria para la política del medio marino.

La LPMM dota al medio marino español de un marco regulador coherente que garantiza un buen estado ambiental. Además, lo lleva a cabo aportando un tratamiento integral del medio marino ${ }^{33}$, porque persigue la gestión de todos los sectores relacionados con el mar de manera integrada con un enfoque ecosistémico $^{34}$.

Esta ley completa la LPNB y tiene por objeto lograr o mantener un buen estado ambiental del medio marino a través de su planificación, conservación, protección y mejora (art. 1.1 LPMM).

Asimismo, otro objetivo de la Ley, dada la naturaleza jurídica del espacio marino como bien de dominio público, es "asegurar un uso sostenible de los recursos del medio marino que tenga en consideración el interés general" (art. 1.2).

\footnotetext{
32 Ibidem, p. 165 y ss. GIMÉNEZ CASALDUERO, “Las áreas marinas protegidas...", op. cit., pp. 8-9. Además, cabe señalar que esta postura fue defendida por el Consejo de Estado en su "Informe sobre la protección de hábitats y especies marinas", elaborado a petición del Gobierno y aprobado el 9 de julio de 2006, en el que se aconsejaba la creación de una o dos nuevas figuras de espacio natural protegido, el AMP y el Área Marítimo-Terrestre Protegida. Disponible en http://www.consejo-estado.es/pdf/especies\%20marinas.pdf (14 de diciembre de 2016).

${ }^{33}$ ARANA GARCÍA, "La Ley 41/2010, de protección...", op. cit. p. 223. Como afirma ORTIZ GARCÍA, con esta ley "se hace justicia con el medio marino, pues se pone en valor per se y es considerado como un todo integrado". ORTIZ GARCÍA, "La red de áreas marinas protegidas...", Arana García y Sanz Larruga (dirs.), La ordenación... op. cit., p. 345.

${ }^{34}$ Esto significa que gestiona de forma integrada todos los sectores relacionados con el mar, pero respetando los ecosistemas. Vid. ORTIZ GARCÍA, "La Ley de protección del medio marino...", op. cit., p. 6.
} 
El instrumento para alcanzar dicho objetivo es una planificación coherente de las actividades que se llevan a cabo en el medio marino. Esta planificación se materializa mediante las llamadas estrategias marinas, que, como veremos en el apartado siguiente, son los instrumentos esenciales de la planificación del medio marino (art. 1.3).

El mencionado buen estado de conservación se define como "aquel en el que éste da lugar a océanos y mares ecológicamente diversos y dinámicos, limpios, sanos y productivos en el contexto de sus condiciones intrínsecas, y en el que la utilización del medio marino sea sostenible, quedando así protegido su potencial de usos, actividades y recursos por parte de las generaciones actuales y futuras", teniendo en cuenta la estructura, el funcionamiento y los procesos de los ecosistemas que componen el medio marino, y los factores fisiográficos, geográficos, biológicos, geológicos y climáticos naturales, además de las condiciones físicas, acústicas y químicas que se derivan sobre todo de la actividad humana interna o externa en la zona en cuestión (art. 9 LPMM).

Los ámbitos de aplicación de la LPMM son todas las "aguas marinas", incluidos el lecho, el subsuelo y los recursos naturales, sometidas a soberanía o jurisdicción española (art. 2.2). En concreto, se entienden incluidos en la categoría de aguas marinas tanto el mar territorial como la zona económica exclusiva del océano Atlántico ${ }^{35}$, la zona económica exclusiva de España en el Mediterráneo noroccidental ${ }^{36}$ y la plataforma continental, así como la zona de protección pesquera para el Mediterráneo ${ }^{37}$. Sin embargo, no resulta de aplicación a las aguas costeras definidas en el texto refundido de la Ley de Aguas $^{38}$. De este modo, la LPMM solo se aplica a los aspectos de la protección

\footnotetext{
${ }^{35}$ Vid. Ley 15/1978, de 20 de febrero, sobre zona económica.

${ }^{36}$ Real Decreto 236/2013, de 5 de abril, por el que se establece la Zona Económica Exclusiva de España en el Mediterráneo noroccidental.

${ }^{37}$ Real Decreto 431/2000, de 31 de marzo, por el que se modifica el Real Decreto 1315/1997, de 1 de agosto, por el que se establece una zona de protección pesquera en el Mediterráneo.

${ }^{38}$ Real Decreto Legislativo $1 / 2001$, de 20 de julio, por el que se aprueba el texto refundido de la Ley de Aguas, artículo 16.1 bis: "Son aguas costeras, las aguas superficiales situadas hacia tierra desde una línea cuya totalidad de puntos se encuentra a una distancia de una milla náutica mar adentro desde el punto más próximo de la línea de base que sirve para medir la anchura de las aguas territoriales y que se extienden, en su caso, hasta el límite exterior de las aguas de transición".
} 
o la planificación del medio marino que no se hayan contemplado en los planes hidrológicos de cuencas en España.

Por tanto, la LPMM se centra en la parte marina del dominio público marítimoterrestre de la Ley de Costas (art. 3), que, como bien indica ORTIZ GARCÍA, era la asignatura pendiente de nuestro ordenamiento jurídico, ya que la Ley de Costas solo se aplica a la parte terrestre del dominio público marítimo-terrestre.

En definitiva, esta norma establece un marco jurídicamente vinculante para la ordenación y gestión de "todo" el espacio marítimo español. Esto es algo inédito y muy necesario en nuestro ordenamiento jurídico, puesto que fija un marco para el espacio marítimo como el que ya existía para el ámbito terrestre ${ }^{39}$.

\section{A. Las estrategias marinas}

Las estrategias marinas suponen el pilar central de esta ley porque a través de su elaboración se crean instrumentos de naturaleza jurídica vinculante en la planificación del medio marino.

De acuerdo con el artículo 7 LPMM, las estrategias marinas son los instrumentos de planificación de cada demarcación marina y constituyen el marco general al que deberán ajustarse necesariamente las diferentes políticas sectoriales y actuaciones administrativas con incidencia en el medio marino, de acuerdo con lo establecido en la legislación sectorial correspondiente.

El apartado segundo del citado precepto dispone que las estrategias marinas no crean por sí solas derechos u obligaciones para los particulares o entidades, por lo que su aprobación o modificación no dará lugar a indemnización. Y es que, como afirma ARANA GARCÍA, estas estrategias responden a la idea de "racionalización de los poderes públicos, ordenando el ejercicio de todas las competencias públicas que concurren en este espacio marítimo" ${ }^{\text {40 }}$.

Por tanto, las estrategias son los instrumentos esenciales de la planificación del medio marino y persiguen los siguientes objetivos específicos: proteger y

\footnotetext{
39 ORTIZ GARCÍA, "La red de áreas marinas protegidas...", op. cit., p. 347.

${ }^{40}$ ARANA GARCÍA, “La Ley 41/2010, de protección...”, op. cit. p. 226.
} 
preservar el medio marino, incluyendo su biodiversidad, evitar su deterioro y recuperar los ecosistemas marinos en las zonas que se hayan visto afectadas negativamente; prevenir y reducir los vertidos al medio marino; y garantizar que las actividades y usos en el medio marino sean compatibles con la preservación de su biodiversidad (art. 1.3 LPMM).

Para conseguir los citados objetivos, las estrategias marinas conllevan una serie de actuaciones: la evaluación del estado ambiental de las aguas marinas (art. 8 LPMM); la definición de un conjunto de características correspondientes a un buen estado ambiental (art. 9.5 LPMM); la fijación de objetivos ambientales asociados a conseguir el buen estado ambiental que previamente se ha definido respecto de cada demarcación marina y de indicadores para poder evaluar la consecución de los objetivos ambientales (art. 10.2 LPMM); un programa de seguimiento coordinado para evaluar periódicamente el estado ambiental del medio marino (art. 11.1 LPMM); y, en último lugar, un programa de medidas para lograr el buen estado ambiental.

Pero estas actuaciones se deben circunscribir a unos determinados ámbitos espaciales denominados demarcaciones marinas (art. 6.2 LPMM).

Las demarcaciones son las subdivisiones de las distintas regiones y subregiones en que se divide el medio marino español. Así, el artículo 6 LPMM fija cinco demarcaciones: la demarcación marina noratlántica; la demarcación marina sudatlántica; la demarcación marina del Estrecho y Alborán; la demarcación marina levantino-balear; y la demarcación marina canaria.

La elaboración de estas estrategias es competencia estatal, lo que responde a la necesidad de garantizar un grado mínimo de homogeneidad que actúe de forma respetuosa con los intereses generales y la ordenación del dominio público $^{41}$. Esto se refleja en la misma Ley a través de la determinación de

\footnotetext{
${ }^{41}$ Las CC. AA. carecen de espacio marino, aunque sí ejercen determinadas competencias en el medio marino, localizadas fundamentalmente en las aguas interiores. Sobre el principio de territorialidad, vid. ORTIZ GARCÍA, La conservación de la biodiversidad marina... op. cit., p. 610 y ss.; CASADO CASADO y FUENTES I GASÓ, Medi ambient... op. cit., p. 50 y ss.; VALENCIA MARTIN, G., "¿De quién es el mar?: La distribución de competencias entre el Estado y las Comunidades Autónomas en materia de protección del medio marino", Sosa Wagner, F. (coord.), El Derecho Administrativo en el umbral del siglo XXI, Libro homenaje a Ramón Martín Mateo, Tirant lo Blanch, Valencia, 2000, p. 3610 y ss.; GARCÍA PÉREZ, M. y SANZ LARRUGA, F. J., "La distribución de competencias en el medio marino", Arana García y Sanz Larruga (dirs.), La ordenación... op. cit., pp. 279-332.
} 
criterios de planificación aplicables a todas las estrategias y la facultad que atribuye al Gobierno para dictar directrices comunes sobre ciertos aspectos del medio marino y así garantizar la coherencia de sus objetivos (art. 4.2 LPMM).

Así, las estrategias marinas deberán ser aprobadas por el Consejo de Ministros mediante real decreto, previo debate en el seno de la Conferencia Sectorial de Medio Ambiente y previo informe de los ministerios y las comunidades autónomas afectados y del Consejo Asesor de Medio Ambiente, una vez cumplido el trámite de información pública (art. 15).

No obstante, el proceso de elaboración y gestión de las estrategias marinas requiere la colaboración y cooperación de todas las administraciones con competencias marinas y costeras incluso a nivel internacional. Además, se garantiza la participación de las CC. AA. en los ámbitos en que dicho proceso afecte a sus competencias, así como en el seguimiento de su aplicación. Así, la cooperación entre la Administración del Estado y las CC. AA. para la elaboración de las estrategias marinas se lleva a cabo a través de la Conferencia Sectorial de Medio Ambiente y mediante la creación de comités de seguimiento de las estrategias marinas para cada una de las demarcaciones marinas, que estarán integrados por representantes de la Administración estatal y la autonómica con competencias en la ejecución de la estrategia correspondiente, para el seguimiento de la aplicación de las estrategias marinas $^{42}$ (art. 22 LPMM).

Además, también se requiere una gestión cooperativa en el ámbito internacional entre el Estado español y los demás Estados que comparten la misma región o subregión marina para asegurar la coherencia y coordinación de las estrategias de la misma zona. En el seno de la Unión Europea, corresponde a la Comisión garantizar la coherencia de las acciones de los Estados miembros, los cuales deben presentarle los datos sobre los elementos de sus estrategias en cada etapa de su elaboración. Estos datos serán evaluados por la Comisión, que orientará a los Estados miembros para garantizar el cumplimiento de la estrategia y la coherencia de las medidas contempladas (art. 12 Directiva Marco sobre la Estrategia Marina).

\footnotetext{
${ }^{42}$ Estos comités elevarán a la Conferencia Sectorial de Medio Ambiente informes periódicos sobre el cumplimiento de las estrategias marinas.
} 


\section{B. La Red de Áreas Marinas Protegidas}

La LPMM crea formalmente la Red de Áreas Marinas Protegidas de España ${ }^{43} y$ determina sus objetivos, los espacios naturales que la conforman y los mecanismos para su designación y gestión. Esta integra diferentes espacios de protección situados en el medio marino español con independencia de que su declaración y gestión estén reguladas por normas internacionales, comunitarias y estatales, así como su marco normativo y el sistema de relaciones necesario para su funcionamiento. De este modo, se pretende englobar las diferentes figuras de protección del medio marino buscando una mayor interrelación y equilibrio de los objetivos que todas ellas persiguen individualmente ${ }^{44}$.

Dado el carácter ambiental de la LPMM, esta red constituye una pieza fundamental para la conservación de la biodiversidad a largo plazo mediante la designación, protección y conservación de áreas clave, áreas prioritarias para las especies, hábitats y procesos ecológicos que albergan, estableciendo los mecanismos para una gestión responsable ${ }^{45}$.

Los objetivos de la Red son: asegurar la conservación y recuperación del patrimonio natural y la biodiversidad marina; proteger y conservar las áreas que mejor representan el rango de distribución de las especies, hábitats y procesos ecológicos en los mares; fomentar la conservación de corredores ecológicos y la gestión de aquellos elementos que resulten esenciales o revistan primordial importancia para la migración, la distribución geográfica y el intercambio genético entre poblaciones de especies de fauna y flora marina; y constituir la aportación del Estado español a las redes europeas y paneuropeas que, en su caso, se establezcan, así como a la Red Global de Áreas Marinas Protegidas (art. 25 LPMM). Entre los objetivos citados, es claro el predominio de los objetivos ecológicos.

\footnotetext{
${ }^{43}$ Como hemos analizado en apartados anteriores, la LPNB crea la figura de las áreas marinas protegidas como una de las categorías de espacios naturales protegidos, y determina que estas áreas se integrarán en la Red de Áreas Marinas Protegidas (art. 32). Pero no es hasta la aprobación de la LPMM que efectivamente se regula la Red.

${ }^{44}$ ARANA GARCÍA, "La Ley 41/2010, de protección...", op. cit., p. 228.

${ }^{45}$ Vid. ORTIZ GARCÍA, "La red de áreas marinas protegidas...", op. cit., p. 362; ORTIZ GARCÍA, "La Ley de protección del medio marino...", op. cit., p. 22.
} 
i. Los espacios marinos incluidos y su atribución competencial

Como ya se ha comentado, la Red de Áreas Marinas Protegidas está constituida "por espacios protegidos situados en el medio marino español, representativos del patrimonio natural marino, con independencia de que su declaración y gestión estén reguladas por normas internacionales, comunitarias y estatales, así como su marco normativo y el sistema de relaciones necesario para su funcionamiento" (art. 24 LPMM).

La tipología de áreas incluidas en la Red se encuentra regulada en el artículo 26 LPMM y responde a dos criterios: el competencial —estatal y autonómicoy el material —biodiversidad y pesca ${ }^{46}$.

Desde la perspectiva competencial, la Ley alude en primer lugar a las competencias estatales. En efecto, el catálogo comienza con el genérico "Áreas Marinas Protegidas". Así, la Administración estatal ${ }^{47}$ declarará AMP mediante real decreto cuando se trate de espacios, hábitats o áreas críticas situados en áreas marinas bajo soberanía o jurisdicción nacional. No obstante, si existe "continuidad ecológica" 48 del ecosistema marino con el espacio natural terrestre objeto de protección serán de competencia autonómica (art. 26.3).

En el mismo sentido, el artículo 37 LPNB establece que, "en los casos en que exista continuidad ecológica del ecosistema marino con el espacio natural terrestre objeto de protección, avalada por la mejor evidencia científica existente", dichas funciones corresponderán a las CC. AA.

Esta excepción por razón de la llamada "continuidad ecológica" supone un elemento de interconexión entre la LPMM y la LPNB y una forma de

\footnotetext{
${ }^{46}$ Las reservas marinas pesqueras se regulan en la Ley $3 / 2001$, de 26 de marzo, de Pesca Marítima del Estado. Sobre el sector pesquero, véase CONDE ANTEQUERA, J., "Sector pesquero y acuicultura: su relación con el medio ambiente y la ley de protección del medio marino", Arana García y Sanz Larruga (dirs.), La ordenación... op. cit., pp. 529-569.

${ }^{47}$ A través de la Secretaría General del Mar.

${ }^{48}$ Expresión del Tribunal Constitucional en su Sentencia 38/2002, de 14 de febrero, sobre esta cuestión.
} 
participación de las CC. AA. en la protección de estos espacios marinos protegidos $^{49}$.

Pero esta continuidad ecológica se vincula con aquellos espacios terrestres que ya han sido protegidos, porque lo que en realidad el legislador hace, como afirma ORTIZ GARCÍA, es incorporar al derecho positivo la práctica de algunas comunidades costeras de declarar espacios terrestres protegidos que comprenden espacios marinos colindantes ${ }^{50}$.

Desde la perspectiva material -en concreto, de la protección de la biodiversidad-, cabe destacar las AMP del Estado (art. 26.1 a) LPMM) y las zonas especiales de conservación (ZEC), procedentes de la Directiva de Hábitats, y las zonas de especial protección para las aves (ZEPA), procedentes de la Directiva de Aves, que conforman la Red Natura 2000 (art. 26.1 b) LPMM).

Bajo el criterio de la biodiversidad, también pueden formar parte de la Red otras áreas marinas protegidas existentes en el ordenamiento jurídico español a través de la ratificación y publicación de tratados internacionales, como pueden ser las reservas de la biosfera, los lugares Patrimonio Mundial de la UNESCO, los humedales Ramsar, las zonas especialmente protegidas de importancia para el Mediterráneo establecidas en el Convenio de Barcelona y las áreas marinas protegidas en el Convenio OSPAR, entre otras (art. $26.1 \mathrm{~d}$ ) LPMM), así como, sin lugar a dudas, las clásicas figuras de espacios naturales protegidos, según establece el artículo 30 LPNB.

Ante esta tipología de áreas incluidas en la Red, sorprende que no aparezca expresamente la figura de los parques nacionales marinos. No obstante, esta tipología puede considerarse incluida mediante una interpretación de la remisión que la LPMM realiza a la $\mathrm{LPNB}^{51}$.

\footnotetext{
${ }^{49}$ ARANA GARCÍA, "La Ley 41/2010, de protección...", op. cit., p. 229. En este sentido se pronuncia la STC 38/2002, de 14 de febrero.

${ }^{50}$ ORTIZ GARCÍA señala que este modus operandi se inició con el Parque Nacional de Doñana, al que siguió el Parque Nacional de Timanfaya. Vid. ORTIZ GARCÍA, "La red de áreas marinas protegidas...", op. cit., p. 368.

${ }^{51}$ ORTIZ GARCÍA resalta la necesidad de que la Ley prevea de forma expresa los parques nacionales marinos: "[...] qué necesidad hay de hacer interpretaciones tan forzadas, tratándose de espacios de tanta calidad y cantidad de biodiversidad marina". Además, hace referencia a que dichos espacios pueden formar parte a su vez de otras redes, como la Red Natura 2000, lo
} 
Además, como consecuencia del título de intervención "Pesca", también forman parte de la Red las "reservas marinas" 52 . Pero, sobre la base de la atribución competencial que efectúan los artículos 148.1.11 y 149.1.19 CE, las localizadas en aguas interiores (art. 26.3) serán autonómicas, mientras que las localizadas en aguas exteriores serán estatales (art. 26.1 e).

También se atribuye al ministerio correspondiente la competencia para establecer los criterios de integración en la Red de los espacios de competencia estatal (art. 26.2 LPMM) ${ }^{53}$. Por otro lado, los espacios marinos protegidos cuya declaración y gestión sea competencia autonómica deberán cumplir los criterios mencionados para poder formar parte de la Red (art. 26.3 LPMM).

Respecto a este criterio de atribución competencial, consideramos que hubiera sido más eficiente que el legislador fijara un criterio concreto, como podría ser una distancia o un ámbito determinado, y así evitar conflictos competenciales cada vez que se decide declarar un espacio mixto ${ }^{54}$.

que conlleva que no se entienda "que dichos parques nacionales marinos formen parte de redes marinas foráneas y no en cambio de la nuestra, al menos de forma expresa". Vid. ibidem, p. 366.

${ }^{52}$ Reguladas en el artículo 14 de la Ley 3/2001, de 26 de marzo, de Pesca Marítima del Estado.

${ }^{53}$ Estos criterios se han fijado mediante el Real Decreto 1599/2011, de 4 de noviembre, por el que se establecen los criterios de integración de los espacios marinos protegidos en la Red de Áreas Marinas Protegidas de España. Así, el artículo 5 del citado Real Decreto determina que, para la integración de un espacio protegido en la Red, se valorarán los siguientes criterios: su representatividad; su carácter único o rareza; su importancia para hábitats o especies amenazados, en peligro, en declive o regresión; su grado de naturalidad; su vulnerabilidad, fragilidad, sensibilidad, o lenta recuperación de sus hábitats o especies; su nivel de resiliencia; su contribución a la conectividad; su importancia para el desarrollo de alguna de las fases del ciclo biológico de ciertas especies; y su productividad biológica. Pero, además, en todo caso, para su integración en la Red, un espacio deberá: "a) Tener la extensión adecuada que garantice el mantenimiento de las características físicas, geológicas y biológicas, y asegure el funcionamiento de los procesos ecológicos presentes. b) Contar con una proporción relevante de los hábitats o especies por los cuales el espacio ha sido protegido, así como con adecuados tamaños poblacionales de especies que permitan mantener o alcanzar su estado de conservación favorable [...]. c) Disponer del inventario de los componentes de la biodiversidad y los recursos naturales. Para ello se utilizará la mejor información científica disponible. d) Estar debidamente delimitado, georreferenciado y cartografiado".

${ }^{54}$ En este sentido, ORTIZ GARCíA pone como ejemplos los sistemas de algunos países, como los Estados Unidos, que contemplan distancias y límites para atribuir la competencia. Así, en "Estados Unidos, los estados federales pueden crear áreas marinas protegidas hasta una distancia de tres millas náuticas - que coincide con la antigua anchura del mar territorial. Con base en la Submerged Land Act de 1953, que les concede la 'propiedad' del lecho, subsuelo y recursos piscícolas hasta esa distancia. El Estado federal puede crear áreas marinas protegidas, los llamados 'santuarios marinos', a partir de esa distancia, de esas tres millas 
Sin embargo, el Tribunal Supremo (TS) ya ha establecido algún criterio más concreto, siguiendo en parte la doctrina del TC. Así, considera que las competencias autonómicas en materia ambiental se extienden a las aguas interiores y a los islotes situados en estas, pero no alcanzan a las aguas exteriores ni a los islotes situados en estas, salvo circunstancias excepcionales debidamente justificadas, por no ser territorio autonómico ${ }^{55}$.

En suma, las comunidades autónomas son competentes para declarar y gestionar las áreas marinas protegidas mixtas, aunque con el límite de las aguas exteriores, mientras que el Estado es el competente para declarar y gestionar, a sensu contrario, las áreas marinas protegidas situadas en las aguas exteriores. No obstante, debido a la alusión legal de la "continuidad ecológica", esta regla competencial no es tan sencilla ${ }^{56}$.

Como señala el artículo 28 LPMM, la Administración general del Estado realizará las siguientes funciones: "[p]roponer a las instituciones europeas y órganos internacionales, según corresponda, la inclusión en redes internacionales, de aquellos espacios marinos de la Red de Áreas Marinas Protegidas de España que cumplan con los requisitos exigidos por sus respectivas categorías de protección"; "[e]laborar, junto con las Comunidades Autónomas litorales competentes en la declaración y gestión de Áreas Marinas Protegidas, la propuesta de los criterios mínimos comunes para la gestión coordinada y coherente de la Red de Áreas Marinas Protegidas de España, que aprobará la Conferencia Sectorial de Medio Ambiente, y el Plan Director de la Red de Áreas Marinas Protegidas de España"; "[r]ealizar el seguimiento y evaluación, tanto de la Red como de sus directrices comunes"; "[f]omentar y proponer instrumentos de cooperación para la consecución de los objetivos de la Red de Áreas Marinas Protegidas de España en su conjunto"; "[r]epresentar

marinas. Para completar la experiencia norteamericana hay que referirse a otra ley, la Coastal Zone Management Act de 1972, que permite a los estados federales obtener fondos del Gobierno federal para el estudio y ejecución de planes de gestión en su litoral e incluye asimismo la posibilidad de establecer áreas marinas protegidas. De esta manera, el Estado federal conseguía intervenir en esas tres primeras millas marinas sin usurpar los derechos de Ios estados". ORTIZ GARCÍA, "La red de áreas marinas protegidas...", op. cit., pp. 368-369. Vid. también ORTIZ GARCÍA, La conservación de la biodiversidad marina..., op. cit., p. 652.

${ }^{55}$ STS 2786/2011, de 10 de mayo, en relación con el Plan de Ordenación de los Recursos Naturales de la Serra Gelada y de su zona litoral.

${ }^{56}$ ORTIZ GARCÍA, “La red de áreas marinas protegidas...", op. cit., p. 369. 
a España en las redes internacionales de Áreas Marinas Protegidas y establecer mecanismos de cooperación internacional que permitan la proyección externa de la Red"; y "[l]a elaboración de una memoria anual de seguimiento de las actuaciones de la Red de Áreas Marinas Protegidas de España y de informes trienales de situación de la Red"57.

Asimismo, corresponde al ministerio competente la aprobación y aplicación de los planes estatales de recuperación y conservación de especies marinas incluidas en el Catálogo Español de Especies Amenazadas ${ }^{58}$.

ii. El Plan Director de la Red de Áreas Marinas: instrumento de coordinación de las comunidades autónomas y el Estado

De manera general, podemos afirmar que la tutela y el seguimiento de la Red corresponden al Estado. No obstante, dada la concurrencia de competencias en el mismo espacio marítimo, es necesaria e imprescindible la colaboración entre las administraciones concernidas, que se ve en gran medida facilitada por la estrategia marina ${ }^{59}$, en cuya elaboración deben participar tanto el Estado como las CC. AA. al ser titulares de competencias sectoriales marítimas. Pero esto no puede suponer una centralización de las competencias ni la política integrada debe ser la excusa para modificar el sistema competencial vigente ${ }^{60}$. De este modo se fomenta la coordinación de las comunidades autónomas con el Estado para lograr una política integradora. Por ello, el Plan Director de la Red de Áreas Marinas Protegidas se regula en el artículo 29 LPMM. Este se configura como el instrumento básico de coordinación para alcanzar los objetivos de la Red de Áreas Marinas Protegidas de España ${ }^{61}$.

\footnotetext{
${ }^{57}$ Art. 28 apartados b), d), e), f), g) y j) LPMM.

${ }^{58}$ Real Decreto 139/2011, de 4 de febrero, para el desarrollo del Listado de Especies Silvestres en Régimen de Protección Especial y del Catálogo Español de Especies Amenazadas.

${ }^{59}$ ORTIZ GARCÍA, “La red de áreas marinas protegidas...", op. cit., p. 371.

${ }^{60}$ ORTIZ GARCÍA, “La Ley de protección del medio marino...", op. cit., p. 15.

${ }^{61}$ La planificación es una técnica consustancial a la gestión de las AMP y por ello se habla de la "planificación de la gestión". Como es sabido, la gestión no comprende únicamente el ejercicio de actividades estrictamente ejecutivas, sino que abarca también otras potestades como la potestad planificadora. Vid. MARTíN MATEO, R., Tratado de Derecho Ambiental, vol. III, Trivium, Madrid, 1997, p. 355.
} 
Este plan se aprueba mediante real decreto con un procedimiento con participación pública y de las Comunidades Autónomas afectadas y será sometido a evaluación ambiental estratégica (art. 29.3 LPMM).

Este instrumento tendrá una vigencia máxima de diez años y contempla los objetivos a alcanzar en materia de cooperación y colaboración con otras administraciones $\mathrm{u}$ organismos, tanto en el ámbito nacional como en el internacional. El Plan Director también incluirá las directrices para la planificación y la conservación de las áreas marinas protegidas. En definitiva, el Plan Director establecerá los criterios generales de gestión y de planificación para todas las AMP, regulando sus usos y actividades (art. 29.1 LPMM).

Este tipo de medidas contribuye a la creación de un marco homogéneo en todas las áreas de conservación, ya que este plan se convierte en la pieza clave de la coordinación, estableciendo no solo las directrices de obligado cumplimiento para los espacios marinos, sino también las actuaciones para mantener la coherencia interna y la imagen de la $\operatorname{Red}^{62}$.

Por tanto, el Plan Director es el documento de planificación, instrumento básico de coordinación y ordenación de la Red y de cada uno de los espacios marinos, y de los demás instrumentos de planificación, ya que, como especifica el artículo 32.2 LPNB, "se aprobarán planes o instrumentos de gestión que establezcan, al menos, las medidas de conservación necesarias y las limitaciones de explotación de los recursos naturales que procedan para cada caso y para el conjunto de las áreas incorporables a la Red de Áreas Marinas Protegidas de España". De forma que todos los instrumentos de planificación se ajustarán, en última instancia, al Plan Director de la Red.

\section{EL NUEVO MARCO PARA LA ORDENACIÓN DEL ESPACIO MARÍTIMO: EL REAL DECRETO 363/2017, DE 8 DE ABRIL}

Mediante el Real Decreto 363/2017, de 8 de abril, por el que se establece un marco para la ordenación del espacio marítimo, se incorpora al ordenamiento jurídico español la Directiva 2014/89/UE del Parlamento Europeo y del

\footnotetext{
${ }^{62}$ ORTIZ GARCÍA, “La red de áreas marinas protegidas...”, op. cit., p. 373.
} 
Consejo, de 23 de julio de 2014, por la que se establece un marco para la ordenación del espacio marítimo, que pretende fomentar el crecimiento sostenible de las economías marítimas, el desarrollo de los espacios marinos y el aprovechamiento sostenible de los recursos marinos.

El objetivo de la Directiva transpuesta es que los Estados inicien un proceso de ordenación del espacio marítimo consistente en analizar y organizar "las actividades humanas en las zonas marinas con el fin de alcanzar objetivos ecológicos, económicos y sociales".

Los Estados miembros son responsables y competentes para determinar, dentro de sus aguas, el formato y el contenido de la ordenación, incluyendo cualquier distribución del espacio marítimo entre las distintas actividades y usos, así como para establecer los mecanismos institucionales oportunos, obligando a adoptar las disposiciones legales reglamentarias y administrativas necesarias antes del 18 de septiembre de $2016^{63}$.

Así, conforme a la citada Directiva, el Estado español está obligado a: notificar las autoridades competentes a la Comisión Europea; determinar y aplicar una ordenación del espacio marítimo a través de la elaboración de planes de ordenación del espacio marítimo a más tardar el 31 de marzo de 2021; y enviar a la Comisión y a cualquier otro Estado miembro interesado copias de los planes de ordenación del espacio marítimo, incluido el material explicativo pertinente existente sobre la aplicación de la citada Directiva, y de todas sus actualizaciones subsiguientes en un plazo de tres meses a partir de su publicación.

\section{Finalidad y objetivos}

La finalidad principal de la ordenación del espacio marítimo es promover el desarrollo sostenible e identificar y gestionar la utilización del espacio marítimo para diferentes usos del mar.

\footnotetext{
${ }^{63}$ El Real Decreto 363/2007 da cumplimiento a esta obligación con un evidente retraso. Este retraso es consecuencia de la situación de interinidad del Gobierno español hasta finales del año 2016.
} 
Señala el preámbulo del Real Decreto 363/2017 que la ordenación del espacio marítimo también "aspira a identificar y promover los usos múltiples, de conformidad con las políticas y normativas nacionales pertinentes. Para ello, se debe garantizar al menos que el proceso o procesos de planificación culminen en una planificación global, donde se identifique la potencialidad de los espacios marítimos para los diferentes usos y se tengan en cuenta los cambios a largo plazo derivados del cambio climático".

Así pues, la ordenación del espacio marítimo tiene una clara finalidad ambiental, pues con ella se pretende, como afirma el artículo 1 del Real Decreto 363/2017, "fomentar el crecimiento sostenible de las economías marítimas, el desarrollo sostenible de los espacios marinos y el aprovechamiento sostenible de los recursos marinos".

En suma, con el fin de lograr y/o mantener un buen estado ambiental del medio marino, se establece un marco para la ordenación del espacio marítimo que permita una "toma de decisiones coherente, transparente, sostenible y basada en pruebas" 64 .

Este marco dispone la determinación y aplicación de una ordenación del espacio marítimo con el fin de contribuir a los objetivos que se indican en el artículo 5 del Real Decreto 363/2017: “a) Establecerán los objetivos específicos de ordenación en cada demarcación marina, teniendo en cuenta los objetivos ambientales de las estrategias marinas y los objetivos de la planificación sectorial. b) Tendrán en cuenta aspectos económicos, sociales y medioambientales para apoyar el desarrollo y el crecimiento sostenibles en los sectores marítimos, aplicando un enfoque ecosistémico, que promoverá la coexistencia de las actividades y usos pertinentes y el reparto socialmente equitativo del acceso a los usos. c) Contribuirán al desarrollo sostenible de los sectores marítimos, entre otros, la pesca, la acuicultura, el turismo, el patrimonio histórico, el transporte marítimo, y los aprovechamientos energéticos y de materias primas en el mar, sin menoscabo de la conservación, protección y mejora del medio ambiente marino, incluida la resiliencia a los efectos del cambio climático".

\footnotetext{
${ }^{64}$ Preámbulo del Real Decreto 363/2017.
} 
No obstante, en este listado se debería haber reforzado de forma más explícita la obligatoriedad de que en los espacios protegidos, así como en las áreas marinas de tránsito y de conectividad entre espacios marinos protegidos, prevalezcan los criterios ambientales y ecológicos por encima de otros criterios $^{65}$. Por ello, este marco se configura como "una directriz común a todas las estrategias marinas, de acuerdo con lo establecido en el artículo 4.2.f) de la Ley 41/2010"66.

En efecto, el Real Decreto 363/2017 tiene carácter de reglamento ejecutivo de la Ley 42/2010, cuyo artículo 1 dispone: "La presente Ley establece el régimen jurídico que rige la adopción de las medidas necesarias para lograr o mantener el buen estado ambiental del medio marino, a través de su planificación, conservación, protección y mejora", planificación que está sujeta a los criterios del artículo 4, que, en su apartado 2, señala que el "Gobierno podrá aprobar directrices comunes a todas las estrategias marinas con el fin de garantizar la coherencia de sus objetivos, en aspectos tales como [...] f) La ordenación de las actividades que se llevan a cabo o pueden afectar al medio marino".

\section{2. Ámbito de aplicación}

El Real Decreto 363/2017 se aplica a todas las aguas marinas ${ }^{67}$, incluidos el lecho, el subsuelo y los recursos naturales, en las que el Estado español ejerza soberanía, derechos soberanos o jurisdicción (art. 2).

Sin embargo, de este ámbito de aplicación, y, por tanto, de los planes de ordenación marítima, se excluyen: a) las actividades cuyo único propósito sea la defensa o la seguridad nacional; b) la ordenación del territorio y urbanismo; y

\footnotetext{
${ }^{65}$ En este sentido se posicionó la Dirección General de Políticas Ambientales y Medio Natural de la Generalitat de Catalunya en las alegaciones presentadas al proyecto de Real Decreto.

${ }^{66}$ Esta ley habilita al Gobierno para establecer directrices comunes a las estrategias marinas en diversos aspectos, como la ordenación de las actividades que se llevan a cabo o puedan afectar al medio marino.

${ }^{67}$ Estas aguas marinas incluyen, según la definición contenida en el artículo 3 d) del Real Decreto 363/2017: "[...] las aguas, el lecho marino y el subsuelo situados más allá de la línea de base que sirve para medir la anchura de las aguas territoriales y que se extienden hasta el límite exterior de la zona en que el Reino de España ejerce soberanía, derechos soberanos o jurisdicción, y el resto de las aguas costeras con arreglo a la definición del artículo 16 bis. 1 del texto refundido de la Ley de Aguas, aprobado por el Real Decreto Legislativo 1/2001, de 20 de julio, su lecho marino y su subsuelo".
} 
c) las aguas costeras que sean objeto de medidas de ordenación del territorio y urbanismo, y las aguas de zona de servicio de los puertos, a condición de que así se establezca en los planes de ordenación del espacio marítimo.

La exclusión de "las actividades cuyo único propósito sea la defensa o la seguridad nacional" reproduce literalmente los mismos términos del artículo 2.2 de la Directiva 2014/89/UE. Se trata, por tanto, de una transposición formal y material de la Directiva.

No obstante, los otros dos ámbitos excluidos sí presentan una problemática competencial $^{68}$. La cuestión relevante es determinar si la posibilidad de que la ordenación espacial marítima se lleve a cabo en ese espacio entra en conflicto con competencias autonómicas de ordenación del territorio y planificación urbanística y de planificación hidrológica.

Sobre este conflicto, el Consejo de Estado consideró, en su Dictamen 167/2017, que con la regulación prevista en el Real Decreto 636/2017 no se vulneran las competencias autonómicas, "ya que el límite interior son las aguas de transición (otra cosa es que tengan competencia respecto de actos concretos 0 de planificación sectorial distinta de la general territorial/urbanística, como puede ocurrir, eso sí, con la competencia de acuicultura), pero ello es objeto de cuidadosa previsión en el artículo 10 del proyecto $[. . .]^{\prime 69}$.

Por tanto, podemos observar que en las aguas planificadas se han incluido aguas que se encuentran tanto en la Ley de Aguas como en la Ley de Costas y en la Ley 41/2010. Así, se produce un solapamiento de la planificación, que debería armonizarse en aplicación del artículo 2.3 de la Directiva 2014/89/UE. Sin embargo, el Consejo de Estado ha estimado que, a pesar de existir solapamiento, este ya se resuelve mediante la aplicación del artículo 2.3 de la Ley 41/2010, el cual dispone que "no obstante lo dispuesto en el apartado anterior, el Título II [...] no será de aplicación a las aguas costeras definidas en el artículo 16 bis del texto refundido de la Ley de Aguas, aprobado por Real Decreto Legislativo $1 / 2001$, de 20 de julio, en relación con aquellos aspectos

\footnotetext{
${ }^{68}$ Cataluña y Galicia presentaron durante la tramitación de la norma alegaciones relativas a esta vulneración de las competencias autonómicas.

${ }^{69}$ Dictamen del Consejo de Estado núm. 167/2017, de 23 de marzo de 2017, p. 23.
} 
del estado ambiental del medio marino que ya estén regulados en el citado texto refundido o en sus desarrollos reglamentarios, debiéndose cumplir, en todo caso, los objetivos ambientales establecidos en virtud de la presente ley y en las estrategias marinas que se aprueben en aplicación de la misma".

Por tanto, es en las aguas costeras donde se produce este conflicto, porque en ellas las comunidades autónomas ejercen diversas competencias exclusivas, como la acuicultura o la pesca marítima, aunque también inciden en ellas determinadas competencias estatales.

Ante esta concurrencia de competencias en un mismo espacio, el Real Decreto $363 / 2017$ solo debe fijar unos criterios de ordenación para garantizar la compatibilidad y la sostenibilidad de los distintos usos y actividades sin afectar a que la determinación de la específica y concreta aptitud ambiental y la autorización o concesión de las actividades correspondan en cada caso a la Administración con competencias sustanciales en la materia ${ }^{70}$.

De esta forma, el Estado, a partir del ejercicio de sus competencias en relación con la legislación básica de medio ambiente (art. 149.1.23 CE) y con las bases y la coordinación de la planificación general de la actividad económica, puede establecer una planificación general de las aguas marinas, incluidas las costeras que no sean objeto de medida de ordenación del territorio y de urbanismo.

Como pone de manifiesto LOZANO CUTANDA, esta interpretación está avalada por la jurisprudencia constitucional ${ }^{71}$.

\section{Los planes de ordenación del espacio marítimo}

La ordenación del espacio marítimo se lleva a cabo, como afirma el artículo 4 del Real Decreto 363/2017, mediante un plan para cada una de las cinco demarcaciones marítimas españolas, que quedaron fijadas en el artículo 6.2 de la Ley 41/2010 (noratlántica, sudatlántica, del Estrecho y Alborán, levantinobalear y canaria). Estos planes tendrán una duración máxima de diez años,

\footnotetext{
${ }^{70}$ LOZANO CUTANDA, B., "Real Decreto 363/2017, de 8 de abril: la ordenación de los distintos usos y de las actividades económicas en el espacio marítimo", Análisis GA\&P, mayo 2017, p. 3.

${ }^{71}$ SSTC 8/2013, 87/2013, 99/2013 y 3/2014
} 
siendo revisables teniendo en cuenta las actualizaciones pertinentes de las estrategias marinas ${ }^{72}$.

De esta forma, la ordenación mediante planes del espacio marítimo constituirá una directriz común a todas las estrategias marinas ${ }^{73}$. Esto explica que durante el procedimiento de elaboración de los planes de ordenación se precisen la colaboración de los diversos departamentos ministeriales ${ }^{74}$, la cooperación de las comunidades autónomas ${ }^{75}$ y la coordinación con la Comisión Europea ${ }^{76}$. Además, también se hace necesaria la participación pública en la tramitación de los planes desde las fases iniciales de la elaboración, informando a todas las partes interesadas y consultando a los grupos de interés y autoridades pertinentes, así como al público afectado ${ }^{77}$.

En el apartado d) del artículo 1 se señala que los planes se aprobarán por el Consejo de Ministros mediante real decreto y se publicarán en el Boletín Oficial del Estado, lo que supone que los planes tendrán fuerza innovadora vinculante. De este modo, se les atribuye fuerza normativa, sin olvidar la conexión con las estrategias de las demarcaciones a las que están íntimamente ligados, dado que la posibilidad de que se puedan realizar actividades dependerá del informe de compatibilidad a que estará sometida la autorización de actividades. Este informe, en todo caso, deberá decidir acerca de la compatibilidad de cada actividad no solo con la estrategia, sino también con el espacio concreto en donde se solicite llevarla a cabo.

\footnotetext{
${ }^{72}$ Art. 7.2 Real Decreto 363/2017.

${ }^{73}$ De acuerdo con el párrafo 2 del artículo 4 de la Ley 41/2010.

${ }^{74}$ Conforme al apartado a) del artículo 7 del Real Decreto 363/2017: "Cada Departamento ministerial afectado [...] realizará un inventario de la distribución de las actividades y usos existentes y, en la medida de lo posible, futuros, recogidos en el artículo 10, y se remitirá a la Dirección General de Sostenibilidad de la Costa y del Mar con anterioridad al 31 de marzo de 2019".

${ }^{75}$ Art. 7.1 d): "La Dirección General de Sostenibilidad de la Costa y del Mar remitirá a la Comisión Interministerial de Estrategias Marinas la propuesta de planes de ordenación de las demarcaciones marinas para su valoración e informe, previa consulta a los Comités de Seguimiento de las Estrategias Marinas, a las comunidades autónomas, al Consejo Asesor de Medio Ambiente y a los departamentos ministeriales afectados, de acuerdo con lo previsto en el artículo 4.3 de la Ley 41/2010, de 29 de diciembre [...]".

${ }^{76}$ Art. 7.1 e): "Se enviarán a la Comisión Europea y a cualquier otro Estado miembro interesado copias de los planes de ordenación del espacio marítimo, incluido el material explicativo pertinente existente sobre la aplicación del presente real decreto, y de todas sus actualizaciones subsiguientes en un plazo de tres meses a partir de su publicación".
}

${ }^{77}$ Art. 8 Real Decreto 363/2017. 
En relación con el valor normativo de los planes, el Consejo de Estado se pronunció en su Dictamen 167/2017 sobre el proyecto de Real Decreto, afirmando que la aprobación de estos mediante acuerdo del Consejo de Ministros "contribuye a la confusión, porque entonces los planes no podrían tener fuerza innovadora vinculante, aunque esta sea mínima; y ello puede llegar a tener efectos no deseables sobre los informes de compatibilidad, al disminuir la fuerza de dichos informes y, en el fondo, la potencial vinculación de la Ley 41/2010 para las estrategias, en lo que a localización de actividades se refiere"78. Por ello, el Consejo de Estado estima que "los futuros planes no deberían aprobarse por mero acuerdo del Consejo de Ministros, sino mediante real decreto, como se aprueban, según el artículo 15 de la Ley 41/2010, las propias estrategias marinas, salvo que incluyan como componente de las mismas los correspondientes planes de ordenación marítima, en cuyo caso tampoco sería necesario el acuerdo del Consejo de Ministros al integrarse en el real decreto aprobatorio de la estrategia".

En suma, la atribución de valor normativo a los planes contribuye a su eficacia al asegurar que parte del contenido pueda tener fuerza vinculante para las administraciones o para los particulares y deba seguir los trámites preceptivos impuestos por la Ley 40/2015, de 1 de octubre, de Régimen Jurídico del Sector Público. Además, el Consejo de Estado estima que, dado que los planes constituyen, tanto en la normativa europea como en su transposición a nuestro ordenamiento jurídico - Ley 41/2010 - una de las medidas que tienen que programar las estrategias marinas, todo su contenido debe publicarse en el BOE.

Estos planes, conforme al artículo 8.1, tendrán que someterse también, por regla general, al procedimiento de evaluación ambiental estratégica. Aunque el citado precepto solo lo establece de forma indirecta ${ }^{79}$, la Directiva 2014/89/UE,

\footnotetext{
${ }^{78}$ El Consejo de Estado se pronunció en su Dictamen núm. 167/2017, de 23 de marzo de 2017, p. 26.

${ }^{79}$ Sobre el Proyecto de Real Decreto, el Consejo de Estado afirmó que tanto la Ley 27/2006, de 18 de julio, por la que se regulan los derechos de acceso a la información, de participación pública y de acceso a la justicia en materia de medio ambiente, como la Ley 21/2013, de 9 de diciembre, de evaluación ambiental, deberían citarse expresamente en el artículo 8 "para que no haya dudas, pese a que con la remisión genérica a 'las disposiciones pertinentes establecidas' se entienda que son aplicables, porque una cuestión tan relevante como esta debe estar clara en el texto y, además, para que en la elaboración de los planes los órganos de
} 
en su considerando 23, sí lo afirma expresamente y también resulta de la regulación del ámbito de aplicación de la Ley 21/2013, de 9 de diciembre.

De esta forma, como resultado de la declaración ambiental estratégica, determinadas zonas eran consideradas de exclusión de ciertas actividades, si bien, como afirma LOZANO CUTANDA, "en las zonas no calificadas de exclusión la determinación de la aptitud ambiental específica y concreta se hará en el procedimiento de evaluación ambiental de cada uno de los proyectos, evaluación esta última que corresponde llevar a cabo a la comunidad autónoma o al Estado, según cual sea la autoridad competente para otorgar las correspondientes concesiones o autorizaciones" ${ }^{20}$.

\section{A. El contenido de los planes de ordenación}

Respecto al contenido de los planes de ordenación del espacio marítimo, el artículo 10 del Real Decreto 363/2017 determina que cada plan establecerá "la distribución espacial y temporal de las correspondientes actividades y usos, existentes y futuros". Entre las actividades y usos e intereses posibles se incluyen: la acuicultura; la pesca; las instalaciones e infraestructuras para la prospección, explotación y extracción de petróleo, gas y otros recursos energéticos, minerales y áridos minerales, y la producción de energía procedente de fuentes renovables; las rutas de transporte marítimo y el tráfico marítimo; las zonas de vertido en el mar; las zonas e instalaciones de interés para la Defensa Nacional; las zonas de extracción de materias primas; los tendidos de cables y de tuberías submarinos; las actividades turísticas, recreativas, culturales y deportivas; la investigación científica; y el patrimonio cultural submarino.

Pero, además de estos usos y actividades, los planes también incluirán los espacios protegidos, los lugares y hábitats que merezcan especial atención por su alto valor ambiental y las especies protegidas, en especial los recogidos en

las demarcaciones marinas programen los trámites en paralelo, de manera funcional, como ocurre en la planificación hidrológica [...], o en la aprobación de las estrategias marinas [...]" (p. 29).

${ }^{80}$ LOZANO CUTANDA, B., "Real Decreto 363/2017, de 8 de abril: la ordenación de los distintos usos y de las actividades económicas en el espacio marítimo", Análisis GA\&P, mayo 2017, p. 4. 
el Inventario Español del Patrimonio Natural y de la Biodiversidad.

También quedan expresamente incluidos los "elementos de entre los listados u otros adicionales que deban formar parte de la infraestructura verde".

De este modo, el Real Decreto 363/2017 ha tenido en cuenta la Ley 33/2015, de 21 de septiembre, por la que se modifica la Ley 42/2007, de 13 de diciembre, del Patrimonio Natural y de la Biodiversidad, cuyo artículo 15 crea la llamada infraestructura verde ${ }^{81}$.

Como señala el citado precepto, para "garantizar la conectividad ecológica y la restauración del territorio español, el Ministerio de Agricultura, Alimentación y Medio Ambiente, con la colaboración de las comunidades autónomas a través de la Comisión Estatal para el Patrimonio Natural y la Biodiversidad, y de otros ministerios implicados, elaborará [...] una Estrategia estatal de infraestructura verde, y de la conectividad y restauración ecológicas".

Además, se establece que "la Estrategia estatal de infraestructura verde tendrá en especial consideración, entre otros, los espacios protegidos, hábitats en peligro de desaparición y de especies en peligro de extinción, áreas de montaña, cursos fluviales, humedales, vías pecuarias, corrientes oceánicas, cañones submarinos, las rutas migratorias que faciliten la conectividad y los sistemas de alto valor natural originados como consecuencia de las buenas prácticas aplicadas por los diferentes sectores económicos, así como los hábitats prioritarios a restaurar, los terrenos afectados por los bancos de conservación de la naturaleza y los instrumentos utilizados por las administraciones competentes en la aplicación del Convenio Europeo del Paisaje".

Para garantizar la compatibilidad y coherencia del Plan con las estrategias marinas, se prevé en el Real Decreto 363/2017 que se coordinarán a través de los comités de seguimiento de las estrategias marinas, la Comisión Interministerial de Estrategias Marinas u otros órganos de coordinación

\footnotetext{
${ }^{81}$ El Consejo de Estado estimó necesario añadir un apartado, artículo o disposición con este contenido. Además, también consideró conveniente añadir en una nueva disposición adicional la coordinación de las actuaciones previstas en el Real Decreto 3636/2017 con las de elaboración de la infraestructura verde, lo que permitiría coordinar los calendarios. Vid. Dictamen del Consejo de Estado núm. 167/2017, de 23 de marzo de 2017, p. 31.
} 
interadministrativa existentes (art. 4).

Es precisamente el contenido de los planes el tema más importante porque, por la aspiración integradora de todos los usos y actividades en los espacios afectados que plantea la Directiva, se debe garantizar que este contenido también sea integral y comprenda todas las actividades y usos citados por este instrumento de planificación ${ }^{82}$.

\section{A MODO DE CONCLUSIONES: HACIA UNA VERDADERA PROTECCIÓN INTEGRADA DEL MEDIO MARINO}

En el ordenamiento jurídico español existen diferentes instrumentos que regulan la protección del medio marino. Pero en los últimos años se ha avanzado hacia un sistema más integrado de protección del medio marino español. Este sistema se caracteriza por la relación que se produce entre diferentes figuras de protección que proyectan su ámbito de aplicación sobre el medio marino.

Como hemos visto, la idea de integridad en la protección del medio marino tiene su origen en la Unión Europea. De acuerdo con esa visión, se aprobaron la Directiva 2008/56/CE del Parlamento Europeo y del Consejo, de 17 de junio de 2008, por la que se establece un marco de acción comunitaria para la política del medio marino —que obliga a los Estados miembros a adoptar las medidas necesarias para lograr o mantener un buen estado medioambiental del medio marino-, y la Directiva 2014/89/UE del Parlamento Europeo y del Consejo, de 23 de julio de 2014, por la que se establece un marco para la ordenación del espacio marítimo.

Este enfoque integral del medio marino se incorporó en nuestro ordenamiento jurídico mediante la aprobación de la LPMM. Esta ley, que transpone la Directiva 2008/56/CE, tiene por objeto la aprobación de medidas encaminadas a "lograr o mantener el buen estado ambiental del medio marino, a través de su planificación, conservación, protección y mejora”.

\footnotetext{
${ }^{82}$ Respecto a la integridad del alcance de los contenidos proyectados en el Real Decreto $363 / 2017$, véase el desglose que se realiza de los espacios y actividades marítimas en el párrafo 2 del artículo 10.
} 
Desde el punto de vista ambiental, se ha destacado la importancia de la citada Ley porque introdujo un nuevo tipo de planificación ambiental, las estrategias marinas. Además, la Ley también se refiere a otros aspectos relativos a la protección del medio marino no regulados previamente en la legislación española, como la Red de Áreas Marinas Protegidas.

Recientemente, la Directiva 2014/89/UE, de 23 de julio, se ha incorporado al derecho español mediante el Real Decreto 363/2017, de 8 de abril, por el que se establece un marco para la ordenación del espacio marítimo. Esta norma, además de transponer la citada Directiva, se articula como "una directriz común a todas las estrategias marinas" aprobada en aplicación del artículo 4.2 de la LPMM. Esto habilita al Gobierno para establecer directrices comunes a las estrategias marinas en la ordenación de las actividades o usos que afectan al medio marino.

De este modo, se vinculan los dos instrumentos de planificación. Por una parte, las estrategias marinas se configuran como el instrumento esencial de planificación del medio marino. Y, por otra, los planes de ordenación del espacio marítimo son los instrumentos que determinan la capacidad del espacio marino para acoger los diferentes usos y actividades a desarrollar en el medio. Esta vinculación es esencial porque ya la LPMM contemplaba la ordenación de las actividades entre las directrices comunes a las estrategias marinas y en los programas de medidas de las estrategias. Pero, sobre todo, es importante para asegurar que se mantiene el buen estado ambiental

Por tanto, como se analiza en este trabajo, la ordenación que establece la LPMM sienta las bases para conseguir la armonización y concreción de la tutela ambiental del medio marino mediante las estrategias marinas. Además, con la aprobación del Real Decreto 363/2017 se da un paso más y se establece un nuevo marco jurídico para la ordenación del espacio marítimo, con el objetivo de fomentar el crecimiento sostenible de las economías marítimas, el desarrollo de los espacios marinos y el aprovechamiento de los recursos marinos.

En suma, consideramos que esta ordenación contribuirá a la gestión eficaz de las actividades marítimas y al aprovechamiento sostenible de los recursos costeros y marinos, asegurando que se mantenga un buen estado ambiental 
del medio marino. Sin duda, esta norma supone un gran avance para la ordenación y gestión integradas de las actividades marítimas y costeras, que generan conflictos importantes ${ }^{83}$.

Pero todos estos instrumentos legales y figuras de protección por sí solos son insuficientes para alcanzar los objetivos que persiguen, ya que, si algo determina la calidad ambiental del medio marino, es la contaminación de origen terrestre. Por consiguiente, es imprescindible coordinar la política marítima integrada con otro tipo de estrategias que actúen en el litoral y que también vayan dirigidas a proteger nuestros mares.

Así, la línea de futuro consistirá en conectar diferentes estrategias ambientales cuyo ámbito común de aplicación es el litoral para, de este modo, conseguir un marco de protección más intenso, desarrollando, como afirma ARANA GARCÍA, una "gestión integrada de gestores integrados", para lo que se han de considerar criterios geográficos, normativos, sectoriales, económicos, sociales y de seguridad, el intercambio de experiencia entre países, análisis, etc. ${ }^{84}$.

A pesar del nivel de protección jurídica del medio marino que se ha alcanzado en España mediante la LPMM y el Real Decreto 363/2017, todavía quedan aspectos a mejorar y a potenciar, como: consolidar la figura de las AMP y a su vez aumentar su número, ya que España tiene todavía pocas; reforzar la idea de la Red de Áreas Marinas Protegidas como un sistema integrado que va más allá de la suma de los espacios que la constituyen; fomentar la investigación marina para conocer mejor el estado de las aguas y de la biodiversidad marina ${ }^{85}$; y aumentar la proyección internacional de la biodiversidad marina española, de forma que se promueva el carácter transfronterizo de la Red de Áreas Marinas Protegidas.

\footnotetext{
${ }^{83}$ En este sentido, SANZ LARRUGA afirma que dicha Directiva le parece de extraordinaria relevancia para la resolución de los importantes conflictos que generan las actividades marítimas, como ha sido el caso de la explotación de hidrocarburos en las islas Canarias. Vid. SANZ LARRUGA, F. J., "Costas y litoral: la conflictividad ambiental procedente del mar", López Ramón, F., Observatorio de políticas ambientales 2015, Thomson Reuters, Cizur Menor, 2015, pp. 485-513.

${ }^{84}$ ARANA GARCÍA, E., "Derecho de costas y protección del medio marino", Torres López, M. A. y Arana García, E. (dir.), Derecho ambiental (Adaptado al EEES), Tecnos, Madrid, 2015, p. 348.

${ }^{85}$ ORTIZ GARCÍA, "La red de áreas marinas protegidas...", op. cit., p. 376; ALONSO GARCÍA, E., "La reciente e inminente legislación sobre conservación y uso sostenible de la biodiversidad del medio marino ¿celebración o reto?”, Ambienta, núm. 94, marzo 2011, p. 73.
} 
En conclusión, podemos afirmar que el medio marino español cuenta con una protección jurídica oportuna. El nuevo marco jurídico para la ordenación del espacio marítimo supone un avance importante porque insta a garantizar un proceso de planificación global donde se identifique la potencialidad de los espacios marítimos para los diferentes usos y se tengan en cuenta los cambios derivados del cambio climático. No obstante, en estos momentos, todavía es pronto para valorar la eficacia de este nuevo marco jurídico.

\section{BIBLIOGRAFÍA}

AGUIRRE I FONT, J. M., "L'impacte de la reforma de la Llei de Costes sobre el règim jurídic del litoral català: especial referència a la reducció de l'espai protegit i a les invasions competencials", Revista catalana de dret públic, núm. 47, 2013.

AGUIRRE I FONT, J. M., El régimen jurídico del litoral catalán. Especial referencia a la reforma de la Ley de Costas operada por la Ley 2/2013 y al nuevo Reglamento General de Costas aprobado por el Real Decreto 876/2014, Atelier, Barcelona, 2014.

AGUIRRE I FONT, J. M., El régimen jurídico del litoral catalán. Especial referencia a la reforma de la Ley de Costas operada por la Ley 2/2013, de 29 de mayo, de protección y uso sostenible del litoral y de modificación de la Ley 22/1988, de 28 de julio, de Costas, Atelier, Barcelona, 2015.

ALONSO GARCÍA, E., "La reciente e inminente legislación sobre conservación y uso sostenible de la biodiversidad del medio marino ¿celebración o reto?", Ambienta, núm. 94, marzo 2011.

ARANA GARCÍA, E., "La Ley 41/2010, de protección del medio marino como nuevo marco de ordenación de los mares y océanos españoles. Consideraciones generales, estructura y contenido de la norma", Arana García, E. y Sanz Larruga, F. J. (dirs.), La ordenación jurídica del medio marino en España. Estudios sobre la Ley 41/2010, de protección del medio marino, Thomson Reuters, Cizur Menor, 2012. 
ARANA GARCÍA, E., "La Ley 2/2013 de Protección y Uso Sostenible del Litoral: las 'soluciones singulares' y las nuevas medidas relativas a los riesgos naturales en la costa", Revista de derecho urbanístico y medio ambiente, núm. 295, 2015, pp. 101-135.

ARANA GARCÍA, E., "Derecho de costas y protección del medio marino", Torres López, M. A. y Arana García, E. (dir.), Derecho ambiental (Adaptado al EEES), Tecnos, Madrid, 2015.

ARANA GARCÍA, E. y NAVARRO ORTEGA, A., "La Ley de Protección y Uso Sostenible del Litoral: ¿un giro hacia lo desconocido?", Revista Vasca de Administración Pública, núm. 97, septiembre-diciembre 2013, pp. 21-60.

CALERO RODRÍGUEZ, J. R., Régimen jurídico de las costas española, Aranzadi, Pamplona, 1995.

CARRO FERNÁNDEZ-VALMAYOR, J. L., FERREIRA FERNÁNDEZ, J. y NOGUEIRA LÓPEZ, A., La nueva regulación de las costas, INAP, Madrid, 2014.

CASADO CASADO, L. y FUENTES I GASÓ, J. R., Medi ambient $i$ ens locals, CEDECS, Barcelona, 2008.

CHINCHILLA PEINADO, J. A., "La Ley 2/2013, de Protección y Uso Sostenible del Litoral, y el Real Decreto 876/2014, de 10 de octubre, por el que se aprueba el Reglamento General de costas", Revista de derecho urbanístico y medio ambiente, núm. 295, 2015, pp. 137-180.

CONDE ANTEQUERA, J., "Sector pesquero y acuicultura: su relación con el medio ambiente y la ley de protección del medio marino", Arana García, E. y Sanz Larruga, F. J. (dirs.), La ordenación jurídica del medio marino en España. Estudios sobre la Ley 41/2010, de protección del medio marino, Thomson Reuters, Cizur Menor, 2012, pp. 529-569.

FUENTES I GASÓ, J. R., "Buenas prácticas y códigos de conducta: ¿Sustitutivos de la legislación?”, Speyerer Forchungsberichte, núm. 281, 2015, pp. 137-168.

GARCÍA PÉREZ, M., "El marco constitucional y legal de los bienes de dominio público marino en España. Ámbito de aplicación, naturaleza y régimen de 
medio marino en la Ley 41/2010, de protección del medio marino", Arana García, E. y Sanz Larruga, F. J. (dirs.), La ordenación jurídica del medio marino en España. Estudios sobre la Ley 41/2010, de protección del medio marino, Thomson Reuters, Cizur Menor, 2012.

GARCíA PÉREZ, M. y SANZ LARRUGA, F. J., "La distribución de competencias en el medio marino", Arana García, E. y Sanz Larruga, F. J. (dirs.), La ordenación jurídica del medio marino en España. Estudios sobre la Ley 41/2010, de protección del medio marino, Thomson Reuters, Cizur Menor, 2012, pp. 279-332.

GARCÍA RICO, E., "La gestión integrada de las zonas costeras: avances recientes", Juste Ruiz, J., Bou Franch, V. (dirs.) y Sánchez Patrón, J. M. (coord.), Derecho del mar y sostenibilidad ambiental en el Mediterráneo, Tirant lo Blanch, Valencia, 2014, pp. 483-498.

GIFREU I FONT, J., "La protección y utilización del demanio marítimo-terrestre a propósito de la reciente jurisprudencia constitucional. Hacia una ordenación integrada y sostenible del litoral de Cataluña", Práctica Urbanística, Sección Estudios, ed. La Ley, núm. 140, 2016, pp. 1-35.

GIMÉNEZ CASALDUERO, M., "Las áreas marinas protegidas: nuevas perspectivas a la luz de la Ley 42/2007, del patrimonio natural y de la biodiversidad", Revista Catalana de Dret Ambiental, núm. 1, 2010.

GONZÁLEZ SALINAS, J., Régimen jurídico actual de la propiedad en las costas, Civitas, Madrid, 2000.

KELLEHER, G., Guidelines for Marine Protected Areas, IUCN, GlandCambridge, 1999.

LOZANO CUTANDA, B., "Real Decreto 363/2017, de 8 de abril: la ordenación de los distintos usos y de las actividades económicas en el espacio marítimo", Análisis GA\&P, mayo 2017.

MARTíN MATEO, R., Tratado de Derecho Ambiental, vol. III, Trivium, Madrid, 1997. 
MEILÁN GIL, J. L., "El concepto de dominio público marítimo-terrestre en el Proyecto de LC", Revista española de Derecho Administrativo, núm. 59, jul.sep., 1988.

MEILÁN GIL, J. L., "El dominio público natural y la legislación de costas”, RAP, núm. 139, ene.-abr., 1996.

MENÉNDEZ REXACH, A., "La configuración del dominio público marítimoterrestre en la LC”, Estudios Territoriales, núm. 34, sep.-dic., 1990.

MENÉNDEZ REXACH, A., "Definición legal de la ribera del mar: novedades del Reglamento de Costas", Revista de derecho urbanístico y medio ambiente, núm. 295, 2015, pp. 17-44.

NÚÑEZ LOZANO, M. C., La reforma de la Ley de Costas de 2013, Tirant lo Blanch, Valencia, 2013.

ORTEGA ÁlVAREZ, L. I., "La protección del medio marino", Lecciones de Derecho de Medio Ambiente, Lex Nova, 2002, pp. 1833-208.

ORTIZ GARCÍA, M., La conservación de la biodiversidad marina: las áreas marinas protegidas, Comares, Granada, 2002.

ORTIZ GARCÍA, M., La gestión eficiente de la zona costera. Los parques marinos. Tirant lo Blanch, Valencia 2003.

ORTIZ GARCÍA, M., "Las áreas marinas protegidas y la ordenación sostenible e integrada del litoral”, Sanz Larruga, F. J. (dir.) y García Pérez, M. (coord.), Estudios sobre la ordenación, planificación y gestión del litoral: Hacia un modelo integrado y sostenible, Fundación Pedro Barrié de la Maza-Instituto de Estudios Económicos de Galicia, A Coruña, 2009.

ORTIZ GARCÍA, M., "La protección del medio marino", Noticias de la Unión Europea, núm. 307, 2010.

ORTIZ GARCÍA, M., "La Ley de Protección del Medio Marino: hacia la gobernanza marítima", Revista Catalana de Dret Ambiental, vol. II, núm. 2, 2011.

ORTIZ GARCÍA, M., "La red de áreas marinas protegidas de España en la protección del medio marino", Arana García, E. y Sanz Larruga, F. J. (dirs.), La 
ordenación jurídica del medio marino en España. Estudios sobre la Ley 41/2010, de protección del medio marino, Thomson Reuters, Cizur Menor, 2012.

PÉREZ GÁlVEZ, J. F. y ALEMÁN MONTERREAL, A. (coords.), Costas y urbanismo: el litoral tras la Ley $2 / 2013$, de protección y uso sostenible del litoral y de modificación de la Ley de Costas, La Ley-El Consultor, Madrid, 2013.

RAMOS ESPLÁ, A., VALLE-PÉREZ, C., BAYLE-SEMPERE, J. T. y SÁNCHEZLIZASO, J. L., Áreas Marinas Protegidas como herramientas de Gestión Pesquera en el Mediterráneo, Serie Informes y Estudios COPEMED, núm. 11, 2004.

RODRÍGUEZ BEAS, M., "El régimen jurídico de las costas. Especial referencia a la reforma de la Ley de Costas a la luz de la jurisprudencia del Tribunal Constitucional más reciente", Revista Catalana de Dret Ambiental, vol. 7, núm. 1, 2016, pp. 1-50.

RODRÍGUEZ LÓPEZ, P., Comentarios a la LC, Doctrina y Jurisprudencia, Dijusa, Madrid, 2003.

SANZ LARRUGA, F. J., "Nuevas orientaciones sobre la ordenación del medio ambiente marino y costero en España", Revista General de Derecho Administrativo, núm. 25, 2010.

SANZ LARRUGA, F. J., "La reforma de la Ley de Costas o la apertura de la Caja de Pandora", Revista Aranzadi de Derecho Ambiental, núm. 25, 2013, pp. $11-20$.

SANZ LARRUGA, F. J., "Temores y expectativas ante la reforma de la ley de Costas", López Ramón, F. (coord.), Observatorio de Políticas Ambientales 2013, Thomson Reuters Aranzadi, Cizur Menor, 2013.

SANZ LARRUGA, F. J., "La reforma de la Ley de Costas o la puesta en valor económico del litoral", López Ramón, F. (coord.), Observatorio de Políticas Ambientales 2014, Thomson Reuters Aranzadi, Cizur Menor, 2014, pp. 463485. 
SANZ LARRUGA, F. J., "Costas y litoral: la conflictividad ambiental procedente del mar", López Ramón, F., Observatorio de políticas ambientales 2015, Thomson Reuters, Cizur Menor, 2015, pp. 485-513.

SANZ LARRUGA, J. (dir.) y GARCÍA PÉREZ, M. (coord.), Estudios sobre la ordenación, planificación y gestión del litoral. Hacia un modelo integrado y sostenible, Instituto de Estudios Económicos de Galicia Pedro Barrié de la Maza, Observatorio del Litoral de la Universidad de A Coruña, A Coruña, 2009.

TORRES-FERNÁNDEZ NIETO, J. J., FERNÁNDEZ DE TROCONIZ, F. C., OLANO ESPINOSA, C., MENÉNDEZ MENÉNDEZ, A., GONZÁLEZ DE OLANO, G., CANCER MICHOT, P. y RISQUETE, J. L., Comentario a la Ley 2/2013, de 29 de mayo, de Protección y Uso Sostenible del Litoral y de Modificación de la Ley 22/1988, de Costas, Thomson Reuters Aranzadi, Cizur Menor, 2014.

UICN, Directrices para las categorías de manejo de áreas protegidas, Centro de Parques Nacionales y Áreas Protegidas (CPNAP) - Centro Mundial de Monitoreo de la Conservación (WCMC), Cambridge, 1995.

UNESCO, Reservas de la Biosfera: la Estrategia de Sevilla y el Marco Estatutario de la Red Mundial, UNESCO, París, 1996.

VALENCIA MARTIN, G., “¿De quién es el mar?: La distribución de competencias entre el Estado y las Comunidades Autónomas en materia de protección del medio marino", Sosa Wagner, F. (coord.), El Derecho Administrativo en el umbral del siglo XXI, Libro homenaje a Ramón Martín Mateo, Tirant lo Blanch, Valencia, 2000.

VILLANUEVA CUEVAS, A., PUNZÓN MORALES, J. y SÁNCHEZ RODRÍGUEZ, F., "La protección medioambiental de las costas", Ortega Álvarez, L. I., Alonso García, M. C. y De Vicente Martínez, R. (coord.), Tratado de derecho ambiental, Tirant lo Blanch, Valencia, 2013.

ZAMBONINO PULITO, M., La protección jurídico-administrativa del medio marino: tutela ambiental y transporte marítimo, Tirant lo Blanch, Valencia, 2001. ZAMORANO WISNES, J., "Ordenación de los espacios marítimos y de las zonas costeras del Mediterráneo", Juste Ruiz, J., Bou Franch, V. (dirs.) y 
Sánchez Patrón, J. M. (coord.), Derecho del mar y sostenibilidad ambiental en el Mediterráneo, Tirant lo Blanch, Valencia, 2014, pp. 471-482. 